\title{
Faulty Line Selection Method for Distribution Network Based on Variable Scale Bistable System
}

\author{
Xiaowei Wang, ${ }^{1}$ Jie Gao, ${ }^{2}$ Guobing Song, ${ }^{1}$ Qiming Cheng, \\ Xiangxiang Wei, ${ }^{3}$ and Yanfang $\mathrm{Wei}^{4}$ \\ ${ }^{1}$ School of Electrical Engineering, Xian Jiaotong University, Xian, Shaanxi Province 710049, China \\ ${ }^{2}$ College of Automation Engineering, Shanghai University of Electric Power, Shanghai, China \\ ${ }^{3}$ College of Information and Electrical Engineering, China Agricultural University, Beijing, China \\ ${ }^{4}$ School of Electrical Engineering and Automation, Henan Polytechnic University, Jiaozuo 454000, China \\ Correspondence should be addressed to Jie Gao; iamgaojie1993@163.com
}

Received 17 June 2016; Accepted 17 July 2016

Academic Editor: Antonio Fernández-Caballero

Copyright (c) 2016 Xiaowei Wang et al. This is an open access article distributed under the Creative Commons Attribution License, which permits unrestricted use, distribution, and reproduction in any medium, provided the original work is properly cited.

\begin{abstract}
Since weak fault signals often lead to the misjudgment and other problems for faulty line selection in small current to ground system, this paper proposes a novel faulty line selection method based on variable scale bistable system (VSBS). Firstly, VSBS is adopted to analyze the transient zero-sequence current (TZSC) with different frequency variety scale ratio and noise intensity, and the results show that VSBS can effectively extract the variation trends of initial stage of TZSC. Secondly, TZSC is input to VSBS for calculation with Runge-Kutta equations, and the output signal is chosen as the characteristic currents. Lastly, correlation coefficients of every line characteristic current are used as the index to a novel faulty line selection criterion. A large number of simulation experiments prove that the proposed method can accurately select the faulty line and extract weak fault signals in the environment with strong noise.
\end{abstract}

\section{Introduction}

As an important part of the power system, distribution network is closely associated with its users and also has direct impact on the users. Data show that $80 \%$ of fault occurring in distribution network is single phase-to-ground fault. When single phase-to-ground fault occurs, the line voltage value is still symmetrical, the fault current is weak, and it could run 1 to 2 hours after fault occurs, which significantly improves the reliability of power supply. However, during the single phase-to-ground fault period, nonfault phase voltage could rise, which will threaten the system insulation and result in interphase shortage, protection tripping, power supply outage, and other problems. Because of the weak fault signal and the harsh working condition, faulty line selection becomes difficult. Therefore, it is necessary to carry out further research in this area $[1,2]$.
At present, scholars have put forward various faulty line selection methods. Based on different characteristic components, faulty line selection methods for single phaseto-ground could be divided into 3 categories, that is, signal injection method [3], steady-state component method [4], and transient component method $[5,6]$. The signal injection method needs additional signal device and its engineering realization is complex. In steady-state component method the characteristic signal is weak, which makes the result unreliable, while the transient characteristics method is more reliable and applicable because the transient characteristics component is larger than steady component and it will not be influenced by the arc suppression coil and it will need no additional devices [7-11]. Papers [7, 8] use wavelet transform to extract characteristic information for faulty line selection, but the wavelet transform is easily influenced by noise, and the chosen characteristic frequency band may be nonvalid 


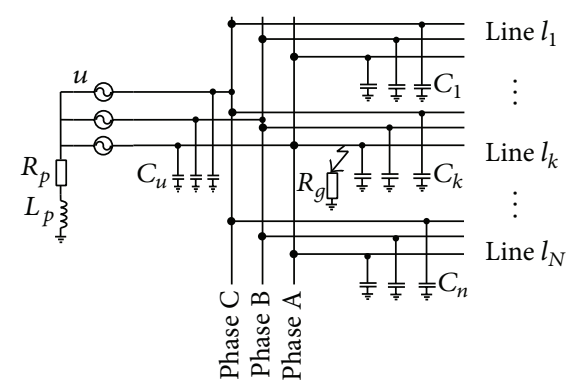

(a) The structure of small current to ground system

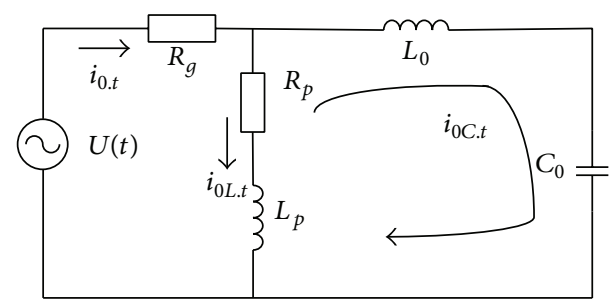

(b) TZSC equivalent circuit of single phase ground

FIGURE 1: The structure and TZSC equivalent circuit of small current to ground system.

transient faulty component. In addition, different wavelet basis function would lead to different extraction results and thus lead to error judgment. Paper [9] adopts Prony algorithm to fit TZSC signal when fault occurs. This method not only effectively avoids the effect of current transformer saturation flux density on collected signals but also improves the overall Prony fitting precision to a certain extent; but its calculation amount is large, its fitting order is difficult to determine, and the antinoise ability is not strong. In [10], the support vector machine shows its advantages in solving the problem of small sample, nonlinear, and high dimensional pattern recognition, but the recognition ability is easily influenced by its own parameters. Paper [11] uses Empirical Mode Decomposition (EMD) of TZSC to extract the five harmonic components in characteristic components and input them into Duffing oscillator to achieve faulty line selection according to the change of phase diagram. But when TZSC is greatly interfered with, modal aliasing phenomenon of EMD would arise and cause error judgment. Paper [12] employs the ratios of the first half-wave extreme and Spectral Kurtosis relative energy entropy from TZSC to build the stepped faulty line selection method. Paper [13] uses the S-transform to obtain the modulus and phase information of electric components at each frequency point, and this information is employed to detect the faulty line. In [14], Hilbert-Huang transform is used to decompose the TZSC, and then the most high frequency component of the intrinsic mode functions (IMF) can be obtained, and, based on this, the selection criterion is built; however, the decomposition process may cause modal aliasing. Paper [15] adopts evidence uncertainty reasoning and compared abnormal events to reduce computation amount and to improve the accuracy of faulty line selection. Paper [16] employs cross-correlation theory to calculate the integrated correlation coefficient of pure fault component of zero-modulus current for each line and takes the line with the smallest one as the faulty line. Paper [17] carries out the wavelet transform to decompose the transient zero-sequence current for each line, calculates the high and low frequency wavelet energies according to the wavelet coefficients, and selects the faulty line according to the maximum value of high or low frequency energy; however, in the strong noise background, the waveform and energy of weak TZSC will be affected.
In recent years, the research on stochastic resonance has made great progress. Stochastic resonance is a new practical technology which uses stochastic resonance principle to detect weak signal, and its research and application have spread into physical fields [18, 19], signal processing $[20,21]$, mechanical fault diagnosis [22], biology [23], neural network [24], and other academic fields; however, the research on this technology in power system is still needed. Therefore, with detailed study of the effect of TZSC on bistable system, this paper proposes a novel faulty line selection method for small current to ground system based on stochastic resonance theory. For signal feature extraction, the method employs VSBS to deal with TZSC and, then, choose the initial stage of output signal as characteristic current; for faulty line selection criterion, a novel faulty line selection criterion, which is based on cross-correlation coefficient sign, is proposed through calculating correlation coefficient of characteristic signal.

\section{Characteristic Analysis of Single Phase-to- Ground Fault}

The structure of small current to ground system is shown in Figure 1(a); when it experiences single phase-to-ground, the TZSC analysis circuit of faulty line is shown in Figure 1(b). In Figure $1, C_{0}$ and $L_{0}$ are zero-sequence capacitance and inductance, respectively, $R_{g}$ is transition resistance of ground point, $R_{p}$ and $L_{p}$ are, respectively, equivalent resistance and inductance of arc suppression coil, and $U(t)$ is zero-sequence voltage.

When distribution network fault occurs, from Figure 1(b), the TZSC flowing through the fault point $i_{0, t}$ is shown as [25]

$$
\begin{aligned}
i_{0, t}= & i_{0 L, t}+i_{0 C, t} \\
= & I_{L m} \cos \varphi e^{-t / \tau_{L}} \\
& +I_{C m}\left(\frac{\omega_{f}}{\omega} \sin \varphi \sin \omega t-\cos \varphi \cos \omega_{f} t\right) e^{-\delta t}
\end{aligned}
$$

where $i_{0 L, t}$ and $i_{0 C, t}$ are inductive current and capacitive current of TZSC, and its initial values are $I_{L m}$ and $I_{C m}$, respectively $\left(I_{C m}=U_{p h m} \omega C, I_{L m}=U_{p h m} / \omega L\right), U_{p h m}$ is phase voltage amplitude, $\omega$ is angular frequency of power frequency, 
$\omega_{f}$ and $\delta$ are oscillation angular frequency and attenuation coefficient of TZSC, $\tau_{L}$ is decay time constant of inductive current, and $\varphi$ is initial phase angel.

From (1), when single phase-to-ground fault occurs in distribution network, the transient capacitance current has the characteristic of periodic attenuation oscillation. And [1] indicates that the free oscillation frequency of overhead line is within $300 \mathrm{~Hz}$ to $1500 \mathrm{~Hz}$ and the free oscillation frequency of cable lines is $1500 \mathrm{~Hz} 3000 \mathrm{~Hz}$.

In addition, studies show that when single phase-toground fault occurs, the traveling wave pole is consistent with the overall changing trend of initial stage TZSC in transient process, so the mutation direction characteristic of initial stage TZSC can be used to replace the traveling wave polarity characteristic of TZSC, which can greatly reduce the hardware requirements and improve the reliability of faulty line selection [26]. Besides, whether it is big initial fault angle or small initial fault angle, the whole changing trend of faulty line is opposite to that of nonfaulty line in TZSC initial stage. But the introduction of arc suppression coil will greatly reduce ground fault current of distribution network, and when the fault occurs in voltage zero position, the changing trend of the initial stage TZSC is not easy to distinguish, which will make faulty line selection more difficult.

Hence, in some faulty conditions, it can be seen from the above analysis that TZSC of distribution network belongs to weak signal. As stochastic resonance (SR) theory has the unique advantage of amplification and detection of weak signals [27], it is helpful to employ the stochastic resonance theory to detect TZSC which is used to select the faulty line.

\section{Signal-Detecting Ability of Variable Scale Bistable System}

The bistable system for studying stochastic resonance is shown in [28]

$$
s_{p}(t)=\frac{\mathrm{d} x}{\mathrm{~d} t}=-\frac{d\left(-a x^{2} / 2+b x^{4} / 4\right)}{\mathrm{d} x}+s_{i}(t)+\Gamma(t),
$$

where $t$ is time, $s_{i}(t)$ is input signal, $\Gamma(t)$ is noise whose intensity is $D, s_{p}(t)$ is output signal, and $x$ is the speed of Brownian particle.

According to Fokker-Planck equation, the probability distribution function of $x$ is shown in (3) when $s_{i}(t)$ is $A \sin \left(2 \pi f_{0} t\right)$ and $a$ and $b$ are equal to $\mu$ and 1 , where $A$ and $f_{0}$ are the amplitude and frequency of periodic signal:

$$
\begin{aligned}
\frac{\partial \rho(x, t)}{\partial t}= & -\frac{\partial}{\partial x}\left[-\mu x-x^{3}+A \sin \left(2 \pi f_{0} t\right) \rho(x, t)\right] \\
& +D \frac{\partial^{2}}{\partial x^{2}} \rho(x, t) .
\end{aligned}
$$

Since (3) has nonautonomous $-(\partial / \partial x)\left[A \sin \left(2 \pi f_{0} t\right) \rho(x\right.$, $t)]$, it has no steady-state solution; that is, it can not have exact expression. However, in the adiabatic approximation condition with $A \ll 1, D \ll 1$, and $f_{0} \ll 1$, the output

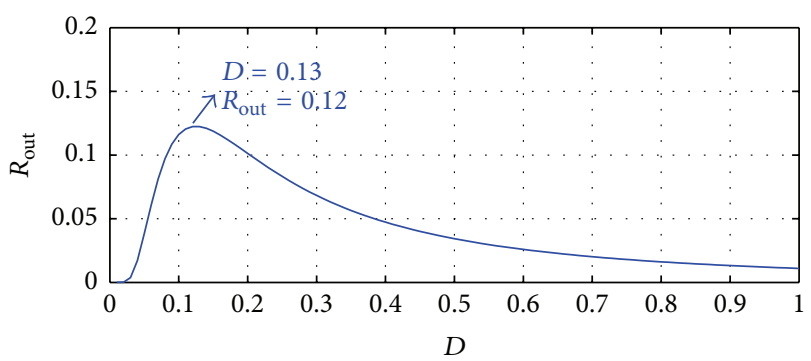

FIgURE 2: The curve of $R_{\text {out }}$ with changed $D$.

signal-to-noise ratio of bistable system can be obtained and shown in

$$
R_{\text {out }}=\frac{\sqrt{2} \mu^{2} A^{2} e^{-\mu^{2} / 4 D}}{4 D^{2}} .
$$

Supposing $\mu$ is 1 and $A$ is 0.2 , the curve of $R_{\text {out }}$ is shown in Figure 2 when $D$ changed. The feature of Figure 2 is that, with the rise of $D, R_{\text {out }}$ presents a trend of increasing and begins to decrease when $D$ reached 0.13 , which is the feature of stochastic resonance. So the bistable system can use noise to increase $R_{\text {out }}$ of signal; that is, the weak signal is amplified and detected.

Under the small parameters of adiabatic approximation condition, the theoretical analysis of stochastic resonance of bistable system coincides with the numerical simulation of the bistable system [28]. However, it is improper to apply the method of small parameters stochastic resonance directly to the processing of signals with large parameters. Reference [27] introduces variable scale stochastic resonance to the process and gets better results; however, when the signal is TZSC, what change will happen to stochastic resonance feature of bistable system, and what rules can we get? This section will focus on the influence of each parameter on bistable system and try to figure out the VSBS characteristics under the effect of TZSC.

3.1. Variable Metric Algorithm and Its Evaluation Index. The principle of variable metric algorithm is to transform high frequency into low frequency in order to make the large parameter signal close to or meeting small parameters conditions of stochastic resonance, which means that the frequency is compressed and then detected by bistable system.

The Calculation Process of Variable Scale. According to the frequency and sampling frequency of signals, a frequency compression-scale ratio (CR) is determined, based on which the compression sampling frequency $f_{s r}$ is defined $\left(f_{s r}=\right.$ $\left.f_{s} / \mathrm{CR}\right)$. Then numerical calculation step $h\left(h=1 / f_{s r}\right)$ is obtained from $f_{s r}$, and, finally, the response output of bistable system is numerically calculated.

Since TZSC are generally broadband signals and their frequency range is not confined to one or a small number of frequencies but distributed in a wide frequency band, to which the traditional signal-to-noise ratio measurement cannot be effectively applied, it is necessary to develop other measurement indexes. 


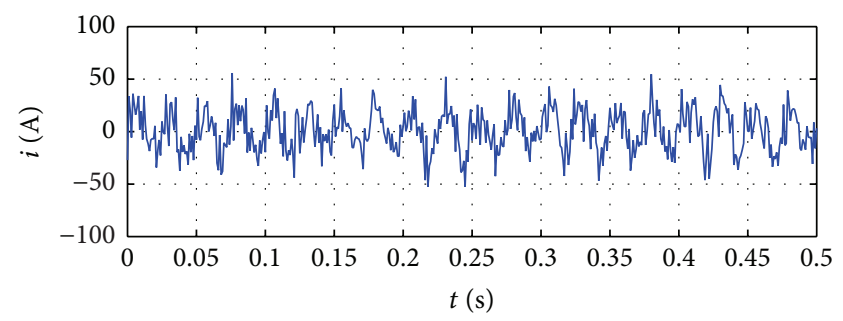

(a) Input signal with noise

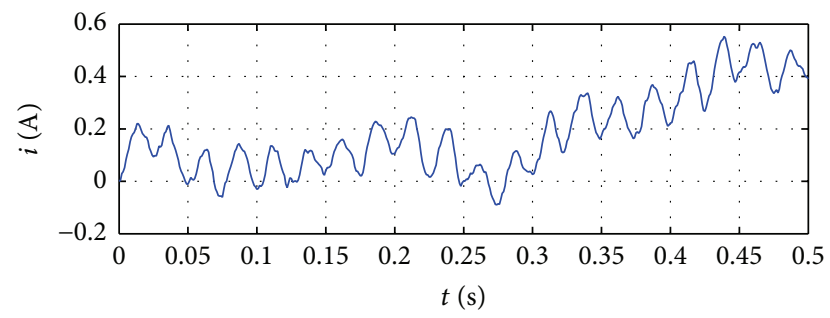

(c) Output signal 1

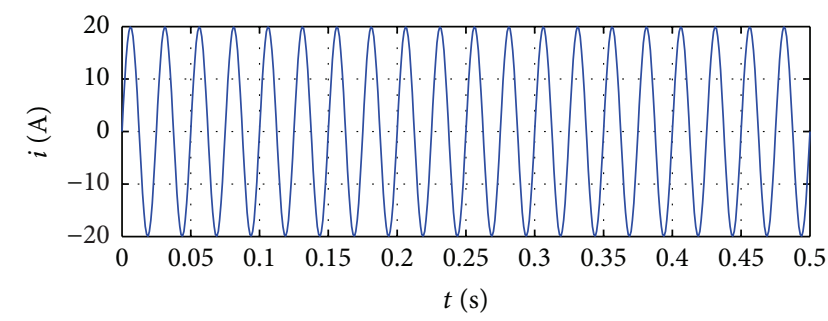

(b) Input signal without noise

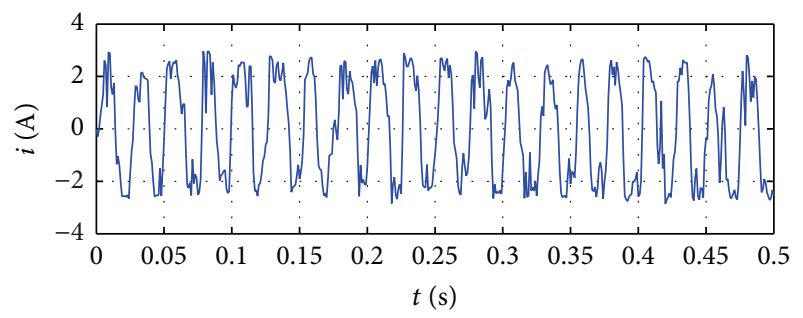

(d) Output signal 2

FIgURE 3: The simulation for bistable system.

Reference [27] shows that although nonlinear Langevin equation cannot accurately predict the motion of Brownian particles, it can well predict the statistical properties of the particle orbits. So, this paper uses cross-correlation coefficient as a measure to describe the response of VSBS whose input signal is weak aperiodic signal. The covariance $\operatorname{Cov}\left(s_{p}(t), s_{i}(t)\right)$ and cross-correlation coefficients $\rho_{p i}$ of two signals are shown in

$$
\begin{aligned}
\operatorname{Cov}\left(s_{p}(t), s_{i}(t)\right) & =E_{\left(s_{p} \cdot s_{i}\right)}-E_{s_{p}} E_{s_{i}} \\
\rho_{p i} & =\frac{\operatorname{Cov}\left(s_{p}(t), s_{i}(t)\right)}{\sqrt{D\left(s_{p}(t)\right)} \sqrt{D\left(s_{i}(t)\right)}} .
\end{aligned}
$$

Additionally, in the initial faulty stage, the overall changing trend of TZSC of faulty line is opposite to that of nonfaulty line, so this paper focuses on the changing trend of input signal and output signal.

\subsection{Simulation of Variable Scale Bistable System}

3.2.1. Simulation of Nonintroducing Variable Scale. Supposing there is a set of measured signals, the sampling points are 500, the corresponding parameters of (2) are $a=b=1, A=20 \mathrm{~A}$, $f_{0}=40 \mathrm{~Hz}$, and $D=100 \mathrm{db}$, respectively, and the value of sampling frequency $f_{s}$ is $1000 \mathrm{~Hz}$. Fourth-order Runge-Kutta algorithm is adopted to calculate (2). And the value of crosscorrelation coefficients $\rho_{p i}$ of $s_{i}(t)$ and $s_{p}(t)$ is -0.0078 , whose results are shown in Figure 3. Figure 3(a) shows the result of $s_{i}(t)$ with noise intensity as $100 \mathrm{db}$, Figure $3(\mathrm{~b})$ shows $s_{i}(t)$ without noise, and Figure 3(c) shows $s_{p 1}(t)$ without being solved by variable scale.

It can be known from Figure 3 and $\rho_{p i}$ that when both weak signal frequencies $f_{0}$ and $D$ are large parameters (larger than 1), the output and input of the system differ dramatically, and the information contained in the output signal will not be able to represent the original signal. That is why the stochastic resonance method with small parameters can not be directly applied to large parameters signal, so the detection is ineffective.

3.2.2. Simulation of Introducing Variable Scale. Bring in variable scale thought, choose CR as 100, $a=b=1, A=20 \mathrm{~A}$, $f_{0}=40 \mathrm{~Hz}, D=100 \mathrm{db}$, and the value of sampling frequency $f_{s}$ is $1000 \mathrm{~Hz}$; calculate (2) with fourth-order Runge-Kutta algorithm and cross-correlation coefficients $\rho_{p i}$ of $s_{i}(t)$ and $s_{p}(t), \rho_{p_{2} i}$ will be obtained, and its value is 0.8088 . The result is shown in Figure 3(d).

Figure 3(d) shows that after the treatment of VSBS, the waveform of output signal $s_{p}(t)$ becomes orderly. Compared to Figure 3(c), the cross-correlation coefficients between $s_{i}(t)$ and $s_{p}(t)$ have obviously improved as well as the amplitude value of $s_{p}(t)$; besides, $s_{p}(t)$ and $s_{i}(t)$ belong to strong correlation. Therefore, through frequency conversion, the disorganized large parameter signal is made clear and orderly; besides, $\rho_{p i}$ is equal to 0.8088 , which indicates that $s_{p}(t)$ could better represent changing trend of $s_{i}(t)$ submerged in noise, achieving the large parameter stochastic resonance or, exactly speaking, a kind of stochastic resonance.

3.3. Transient Zero-Sequence Current Detection. In order to test whether VSBS can detect the TZSC, the ideal TZSC $i_{z}(t)$ [29] is defined as below:

$$
\begin{aligned}
& i_{z}(t)=x_{1}(t)+x_{2}(t)+x_{3}(t)+x_{4}(t)+\Gamma(t), \\
& x_{1}(t)=5.6 \cos \left(2 \pi \times 50 t+60^{\circ}\right), \\
& x_{2}(t)=40 e^{-56 t} \cos \left(2 \pi \times 250 t+30^{\circ}\right), \\
& x_{3}(t)=72 e^{-102 t} \cos (2 \pi \times 315 t), \\
& x_{4}(t)=10 e^{-5.5 t} .
\end{aligned}
$$




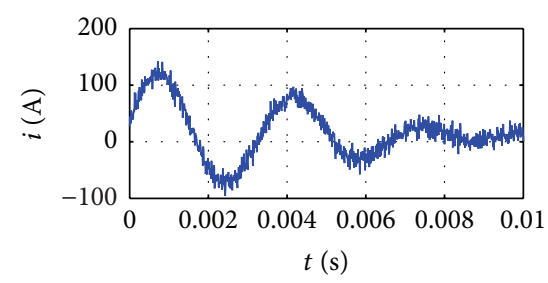

(a) TZSC with noise

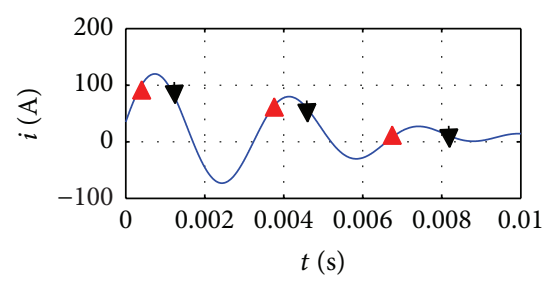

(b) TZSC without noise

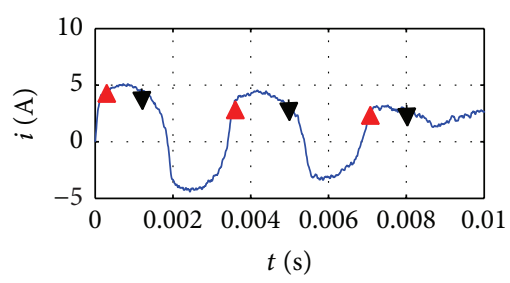

(c) Characteristic current

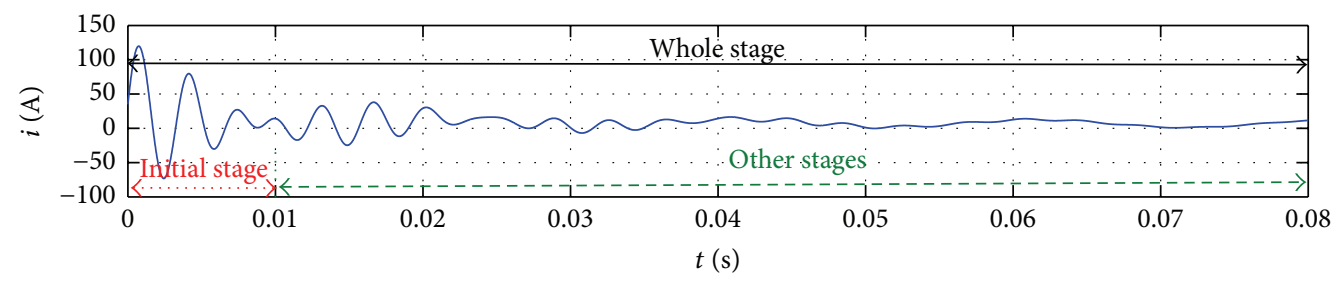

(d) TZSC without noise

FIgURE 4: Characteristic extraction of TZSC by VSBS.

It can be seen that $i_{z}(t)$, which consists of 5 signals, has the characteristic of multifrequency and attenuation; therefore it is a nonperiodic signal. Input it into (2), and its corresponding parameters are $a=b=1$ and $D=50 \mathrm{db}$ and sampling frequency is $f_{s}=100000 \mathrm{~Hz}$. CR is equal to 1000 , and then the results of its numerical simulation are shown in Figure 4.

Definition of Characteristic Current $i_{c}(t)$. Characteristic current is the output signal obtained by solving VSBS with TZSC by fourth-order Runge-Kutta algorithm. Choose nonnoises $i_{z}(t)$ and $i_{c}(t)$ to calculate cross-correlation coefficient $\rho_{c z}$, and the value is 0.7628 .

When only the first $0.01 \mathrm{~s}$ of $i_{z}(t)$ and $i_{c}(t)$ is chosen, as shown in Figure 4(a), the noise causes strong disturbance in the initial stage of $i_{z}(t)$, which makes the changing trend not so clear as the original signal. It is known from Figure 4(c) that, after VSBS treatment, the changing trend of $i_{c}(t)$ is similar to that of $i_{z}(t)$; then, their $\rho_{c z}$ is calculated, and the value has improved to 0.8909 . Therefore, VSBS can effectively extract TZSC changing trend of the initial stage.

This method can be used to better extract the change trend of TZSC in the initial stage. This paper defines $0 \sim 0.01 \mathrm{~s}$ as the initial stage of TZSC, $0.01 \sim \sim \infty$ as noninitial stage, and signal length as the whole stage. To put it vividly, TZSC from (6) is chosen as the label, and the results are shown in Figure 4(d).

3.4. The Detection Adaptability of TZSC. In order to test detection adaptability of VSBS for TZSC, the paper will analyze frequency compression-scale ratio, noise intensity, the initial value, and signal amplitude, respectively.

3.4.1. Frequency Compression-Scale Ratio (CR). Set $a=b=1$ and $D=50 \mathrm{db}$ and sampling frequency $f_{s}$ equals $100000 \mathrm{~Hz}$; set $C R$ as $10,100,1000$, and 5000 , respectively, and the change of $\rho_{c z}$ is shown in Table 1 .

It can be seen from Table 1 that, with the increase of CR, $\rho_{c z}$ between $i_{z}(t)$ and $i_{c}(t)$ first increases and then decreases;
TABLE 1: $\rho_{c z}$ in different conditions.

\begin{tabular}{lcc}
\hline Condition & Whole stage $\rho_{c z}$ & Initial stage $\rho_{c z}$ \\
\hline $\mathrm{CR}=10$ & -0.2220 & -0.3395 \\
$\mathrm{CR}=100$ & 0.4716 & 0.5300 \\
$\mathrm{CR}=1000$ & 0.7628 & 0.8909 \\
$\mathrm{CR}=5000$ & 0.6784 & 0.7944 \\
\hline$D=0$ & 0.7638 & 0.8874 \\
$D=50$ & 0.7628 & 0.8909 \\
$D=100$ & 0.7518 & 0.8876 \\
$D=1000$ & 0.6470 & 0.8641 \\
$D=5000$ & 0.4286 & 0.7910 \\
\hline $\mathrm{IV}=34.8$ & 0.7628 & 0.8909 \\
$\mathrm{IV}=0$ & 0.8806 & 0.9221 \\
$\mathrm{IV}=-34.8$ & 0.8555 & 0.8914 \\
\hline$\tau=1 / 100$ & 0.4807 & -0.0234 \\
$\tau=1 / 10$ & 0.7403 & 0.1820 \\
$\tau=1$ & 0.9221 & 0.7130 \\
$\tau=10$ & 0.7146 & 0.9916 \\
$\tau=100$ & 0.7150 & 0.9922 \\
\hline
\end{tabular}

the reason is that the increase of CR can gradually compress the frequency band range of $i_{z}(t)$ into VSBS's detection range, and there may be a most suitable CR making the input and output most relevant, but when CR continues to increase, excessive frequency compression will also lead to decrease of gap between different frequencies of $i_{z}(t)$, showing the reduction of frequency species, which will further weaken the detection ability of VSBS. In addition, the calculation of cross-correlation coefficients of $i_{z}(t)$ and $i_{c}(t)$ in initial stage shows that $\rho_{c z}$ has greatly improved, and the changing trend of $i_{c}(t)$ is the same as that of $i_{z}(t)$, which verifies that VSBS can effectively extract the changing trend of TZSC in initial stage. 


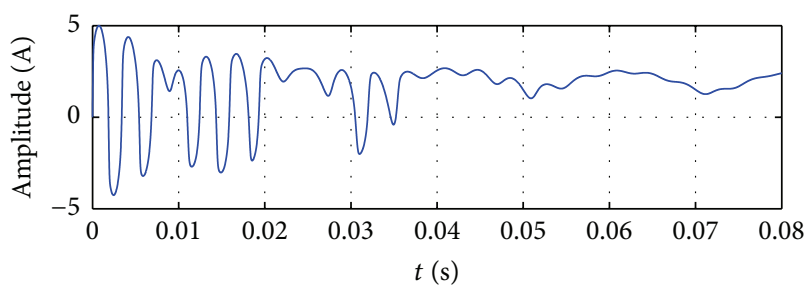

(a) $D=0$

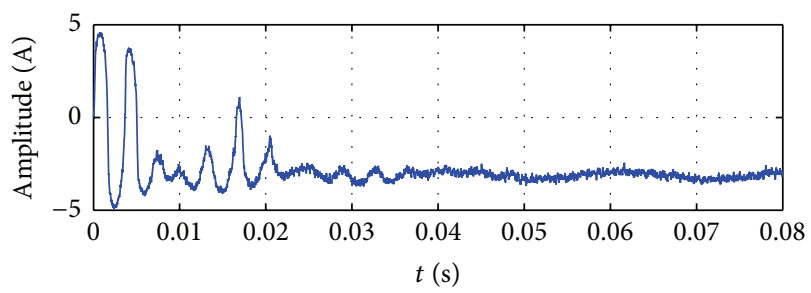

(c) Initial value $=0$

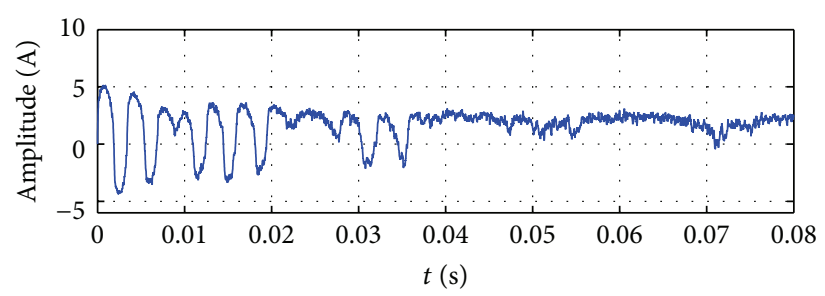

(b) $D=100$

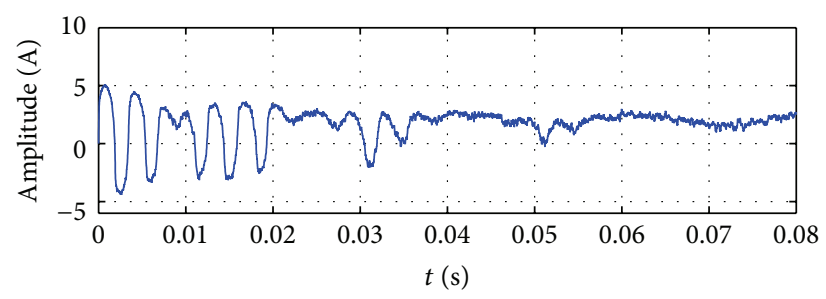

(d) Initial value $=34.8$

Figure 5: Characteristic current under the different conditions.

3.4.2. Noise Intensity (D). Set $a=b=1$, sampling frequency $f_{s}=100000 \mathrm{~Hz}$, and CR $=1000$. Set noise intensity $D$ as $0 \mathrm{db}, 50 \mathrm{db}, 100 \mathrm{db}, 1000 \mathrm{db}$, and $5000 \mathrm{db}$, respectively, and the change of cross-correlation coefficient $\rho_{c z}$ is shown in Table 1 . The change of characteristic current $i_{c}(t)$ is shown in Figure 5(a) when the noise intensity of $i_{z}(t)$ is $0 \mathrm{db}$, and the change of characteristic current $i_{c}(t)$ is shown in Figure 5(b) when the noise intensity of $i_{z}(t)$ is $100 \mathrm{db}$.

It can be seen from waveform in Figure 5 that the amplitude of $i_{c}(t)$ increases with the increase of $D$, which means that part of the noise energy is transferred to $i_{c}(t)$ [27]. In addition, the increases of $D$ made the latter part waveform disorderly; however, the changing trend of the waveform in initial stage is clear which shows no difference with the changing trend of nonnoise; therefore, this once again shows that the VSBS can extract initial stage TZSC. From $\rho_{c z}$ in Table 1 we know that, within a certain range of noise intensity, the increase of $D$ shows little effect on $\rho_{c z}$ of whole stage and of initial stage, which indicates that VSBS can well extract changing trend of TZSC in initial stage with the disturbance of strong noise. However, excessive noise intensity will produce a wide range of interference frequency components, which will affect the existence of the original signal, resulting in the decrease of cross-correlation coefficient and fuzziness of the changing trend in initial stage. It is worth noting that when the noise intensity is 0 , the VSBS can also predict the changing trend of TZSC.

3.4.3. Signal Initial Value (IV). Set $a=b=1, f_{s}=$ $100000 \mathrm{~Hz}, \mathrm{CR}=1000$, and $D=50 \mathrm{db}$; set initial value of $i_{z}(t)$ as 0 and 34.8 , respectively, where 34.8 is initial value (IV) of $i_{z}(t)$. Then carry out numerical simulation and the change of characteristic current $i_{c}(t)$ and cross-correlation coefficient $\rho_{c z}$ is shown in Table 1 and Figure 5. Figure 5(c) is characteristic current $i_{c}(t)$ when initial value of $i_{z}(t)$ is 0 , and Figure $5(\mathrm{~d})$ is characteristic current $i_{c}(t)$ when initial value of $i_{z}(t)$ is 34.8 .
It can be known from Figures 5(c) and 5(d) and Table 1 that when initial value of $i_{z}(t)$ is 0 , the change trend of $i_{c}(t)$ is closest to that of $i_{z}(t)$, especially in the initial stage. Either increase or decrease of the initial value will decrease $\rho_{c z}$, because when initial value of VSBS is 0 , any tiny disturbance is likely to cause it to move in the double potential well with large amplitude, so it can better reflect the moving trend of signals. However, when the initial value is too large, tiny disturbance may not be enough to cause a large amplitude motion in the double well potential or only small range of motion in a single potential well, therefore, it will weaken the detection ability of VSBS, and this is consistent with the decrease of $\rho_{c z}$ in Table 1. Another reason for adopting TZSC to select faulty line in this paper is that when the initial value of TZSC is 0 , VSBS and faulty line selection can be better combined [30].

3.4.4. Signal Amplitude. Set $a=b=1, f_{s}=100000 \mathrm{~Hz}, \mathrm{CR}=$ 1000 , and $D=50 \mathrm{db}$; set the initial value as 0 , increase the amplitude of $i_{z}(t)$, and set the amplitude factor $\tau$ as $1 / 100,1 / 10$, 1,10 , and 100 , respectively.

It is known from Table 1 that, with the increase of amplitude $i_{z}(t)$, cross-correlation coefficient $\rho_{c z}$ of whole stage and initial stage first increases and then decreases, but $\rho_{c z}$ of noninitial stage increases. The reason is that $i_{z}(t)$ belongs to damped oscillation signal, and, compared with that of noninitial stage, the amplitude values of initial stage are always larger, and the detection ability of VSBS on $i_{z}(t)$ in noninitial stage is weaker. Therefore, appropriate increase of signal value would improve detection ability of VSBS.

Based on the above analysis, the features of BSVS detecting TZSC are summarized as follows:

(1) Appropriate frequency compression ratio can improve the signal detection performance.

(2) For small amplitude signal, appropriate increase of amplitude can improve signal detection performance. 
(3) For the signal with zero initial value, VSBS has a better detection performance of changing trend in its initial stage.

(4) The cross-correlation coefficient of whole stage is always smaller than that of initial stage.

\section{Faulty Line Selection Method}

4.1. Parameter Setting. Based on the above analysis, this paper will select faulty line according to the following characteristics of VSBS detecting TZSC:

(1) The overall changing trend of TZSC in initial stage between faulty line and nonfaulty line is opposite.

(2) VSBS has excellent detection ability for the changing trend of TZSC in initial stage.

(3) When single phase-to-ground fault occurs in small current to ground system, the free oscillation frequency of overhead lines is generally $300 \mathrm{~Hz} \sim 1500 \mathrm{~Hz}$, while the free oscillation frequency of cable lines is $1500 \mathrm{~Hz} 3000 \mathrm{~Hz}$. In addition, different fault conditions may cause the TZSC spectrum to transfer into low frequency band [25].

(4) Appropriate increase of signal amplitude helps to improve detection performance of VSBS.

According to (1) and (2), this paper will focus on crosscorrelation coefficient of different lines. Since the TZSC before failure is 0 , when calculating cross-correlation coefficients, we will choose $T / 4$ cycle after fault as the initial stage (0.02 s 0.025s) in the paper; with (3) frequency varieties are compressed as much as possible to make frequency varieties into the frequency range which VSBS can detect, in order to enhance the adaptability of the method; therefore, the frequency compression-scale ratio (CR) is set as 1500. Based on (4) and simulation experiment, when the maximum amplitude of signal is less than 5, we first expand the amplitude by 10 times and then input it into VSBS. In addition, we find that TZSC amplitude before fault is not 0 but a very small value, which needs to be set to 0 before fault.

\subsection{Pretreatment of Faulty Line Selection. Take line $l_{1}$ as an} example:

(1) Choose TZSC of line number 1 from one cycle before fault to one cycle after fault as TZSC $i_{z}(t)$, and set the signal one cycle before fault as 0 .

(2) Judge whether the maximum amplitude of $i_{z}(t)$ is smaller than 5, if it is, carry out (3), and if it is not, carry out (4).

(3) Expand amplitude of $i_{z}(t)$ by 10 times and input it into VSBS to calculate characteristic current $i_{c}(t)$.

(4) Directly input $i_{z}(t)$ into VSBS to calculate characteristic current $i_{c}(t)$.

Calculate $i_{c}(t)$ of all lines according to the above steps.
4.3. Steps of Faulty Line Selection. Take $l_{j}$ as an example to explain the steps of faulty line selection.

Step 1. Calculate cross-correlation coefficients $\rho_{j q}$ between line number $l_{j}(j=1,2,3, \ldots)$ and other lines $l_{q}(q=$ $1,2,3, \ldots q \neq j$ ) in initial stage.

Step 2. Count positive and negative signs of calculated $\rho_{j q}$ :

(1) If all the signs of $\rho_{j q}$ are the same, the output is " -1 " and line $l_{j}$ is judged as faulty line.

(2) If all the signs of $\rho_{j q}$ are not the same, the output is " 1 " and line $l_{j}$ is judged as nonfaulty line.

The remaining lines are also judged with the same steps.

\section{Case Study}

5.1. Simulation Model. ATP-EMTP is used in this paper to simulate the single phase-to-ground fault. The simulation model is shown in Figure 6 and the parameters of simulation model are the same as [31].

5.2. Simulation Results with Changing Phase and Resistance. Build the simulation model according to the parameters, make fault of line $l_{1}$ occur at the point $5 \mathrm{~km}$ from the bus, and change the initial fault angle $\left(0^{\circ}, 30^{\circ}, 60^{\circ}\right.$, and $\left.90^{\circ}\right)$ and ground resistance for simulation. It is known from [25] that when single phase-to-ground fault of the small current to ground system occurs, the fault resistance value is generally $0 \mathrm{k} \Omega$ to $2 \mathrm{k} \Omega$; therefore, the maximum fault resistance is set as $2 \mathrm{k} \Omega$ in the paper. Then, select the faulty line according to the proposed method, and the parameters of VSBS are as follows: $a=b=1$ and $\mathrm{CR}=1500$. In addition, we use $\left(l_{1}, 0^{\circ}\right.$, and $300 \Omega$ ) to indicate the fault occurrence in line number 1 when its initial angle is $0^{\circ}$ and faulty resistance is $300 \Omega$. The results of their specific cross-correlation coefficients are shown in Table 2 in which $\rho_{12}$ represents cross-correlation coefficient of characteristic currents $l_{1}$ and $l_{2}$.

The paper takes $\left(l_{1}, 90^{\circ}\right.$, and $\left.2000 \Omega\right)$ as an example to explicitly show the consequence of VSBS. Under this fault condition, the TZSC of $l_{2}$ and $i_{c}(t)$ of $l_{2}$ are shown in Figures $7(\mathrm{a})$ and $7(\mathrm{~b})$; the cross-correlation coefficients are shown in Table 3.

The comparison of Figures 7(a) and 7(b) shows that, after the treatment of VSBS, the changing speed of $i_{c}(t)$ in initial stage becomes slow, and oscillation part is reduced, which makes the changing trend of $i_{c}(t)$ in initial stage easier to identify than that of TZSC in initial stage. It can be seen from Figure $7(\mathrm{~b})$ that $i_{c}(t)$ waveform of faulty line is steadier than that of nonfaulty lines, because frequency compression makes the part in low frequency band and with strong intensity easy to detect by VSBS, and the part in high frequency band and with weak intensity may be ignored, besides, the intensity of low frequency band fault transient component in the faulty line is much larger than that of nonfaulty line, and, therefore, the characteristic current waveform of faulty line is steadier than that of nonfaulty line. Besides, through simulation, we discover that because the transient 


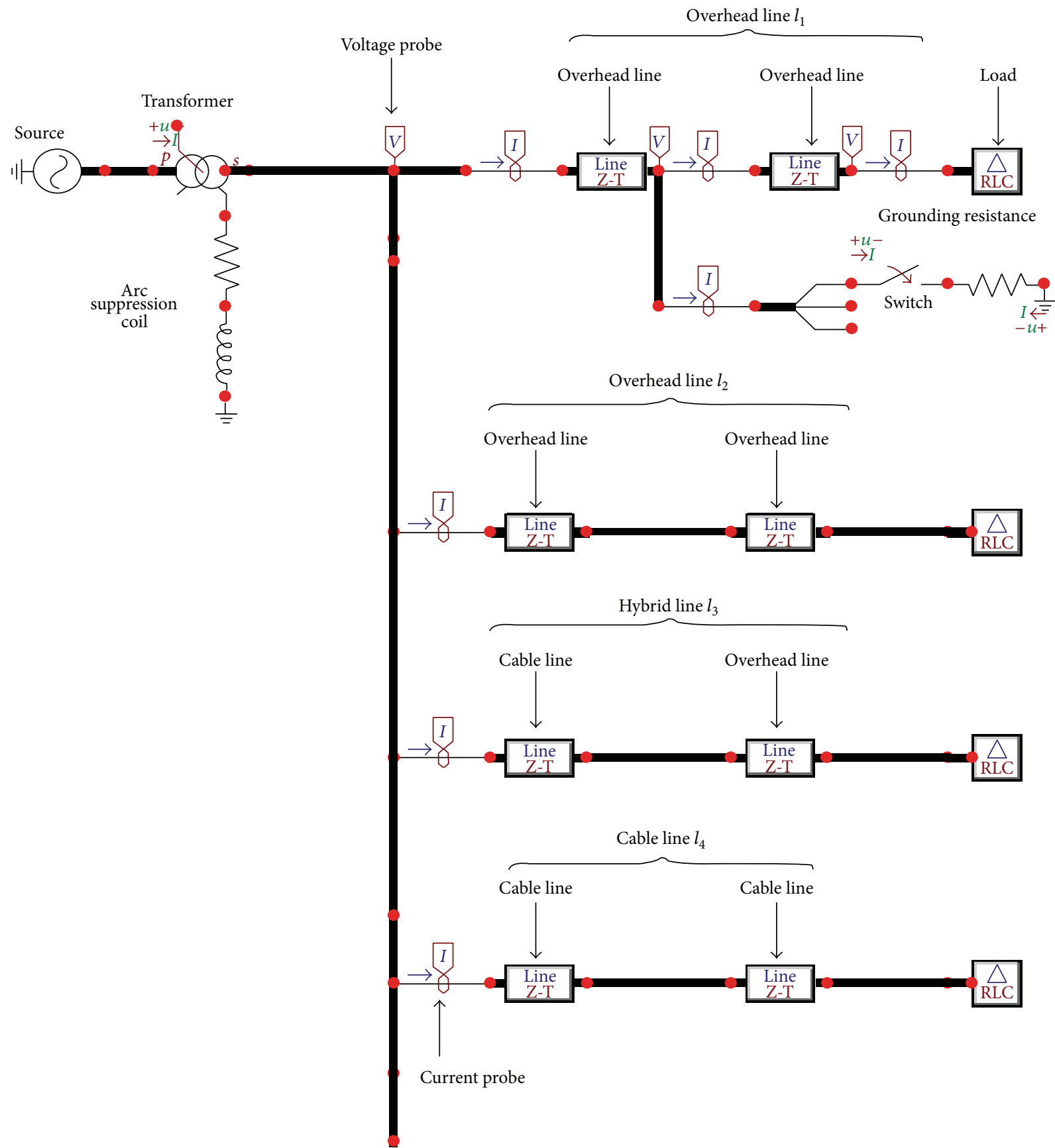

FIGURE 6: ATP simulation model.

free oscillation components and zero-sequence steady-state components are offset, the increase of fault resistance also makes waveform $i_{c}(t)$ of each line steadier.

It can be seen from Table 3 that $\rho_{1 q}$ of $l_{1}$ and other lines are equal to $-0.9732,-0.8092$, and -0.7535 , respectively; since all of them are the same sign, the output is " -1 "; $\rho_{2 q}$ of $l_{2}$ and other lines are equal to $-0.9732,0.7408$, and 0.6597 , respectively; since all of them are not the same sign, the output is " 1 "; therefore, we judged $l_{1}$ as faulty line, and the judging result is consistent with simulation.
In summary, we know from Table 2 that TZSC of various fault conditions is, respectively, input into VSBS, and the output judging results are consistent with actual fault situations. Therefore, the proposed method can accurately achieve faulty line selection under different fault resistance and initial fault angle.

5.3. Simulation Results of Fault with Random Gauss White Noise Added. Since signals collected in actual system with fault often carry noise with them, to verify the antinoise 
TABLE 2: Results of different initial angle and ground resistance.

\begin{tabular}{|c|c|c|c|c|c|c|c|c|}
\hline Faulty line & Fault situation & $\rho_{12}$ & $\rho_{13}$ & $\rho_{14}$ & $\rho_{23}$ & $\rho_{24}$ & $\rho_{34}$ & Judgment result \\
\hline \multirow{24}{*}{$l_{1}$} & $\left(0^{\circ}, 10 \Omega\right)$ & -0.4942 & -0.8054 & -0.9092 & 0.7852 & 0.6078 & 0.7973 & $l_{1}$ fault \\
\hline & $\left(0^{\circ}, 100 \Omega\right)$ & -0.6776 & -0.7360 & -0.7528 & 0.8573 & 0.7034 & 0.8744 & $l_{1}$ fault \\
\hline & $\left(0^{\circ}, 500 \Omega\right)$ & -0.5710 & -0.7146 & -0.6549 & 0.8999 & 0.8369 & 0.9032 & $l_{1}$ fault \\
\hline & $\left(0^{\circ}, 1000 \Omega\right)$ & -0.5991 & -0.3511 & -0.7291 & 0.7810 & 0.7424 & 0.6944 & $l_{1}$ fault \\
\hline & $\left(0^{\circ}, 1500 \Omega\right)$ & -0.6845 & -0.2796 & -0.3330 & 0.7057 & 0.5993 & 0.8385 & $l_{1}$ fault \\
\hline & $\left(0^{\circ}, 2000 \Omega\right)$ & -0.6928 & -0.5382 & -0.5511 & 0.6465 & 0.5293 & 0.8454 & $l_{1}$ fault \\
\hline & $\left(30^{\circ}, 10 \Omega\right)$ & -0.5835 & -0.8295 & -0.9360 & 0.8132 & 0.6362 & 0.7710 & $l_{1}$ fault \\
\hline & $\left(30^{\circ}, 100 \Omega\right)$ & -0.7767 & -0.8968 & -0.8948 & 0.8668 & 0.7265 & 0.8485 & $l_{1}$ fault \\
\hline & $\left(30^{\circ}, 500 \Omega\right)$ & -0.7987 & -0.8858 & -0.8773 & 0.8746 & 0.8609 & 0.9254 & $l_{1}$ fault \\
\hline & $\left(30^{\circ}, 1000 \Omega\right)$ & -0.7353 & -0.6373 & -0.7927 & 0.8598 & 0.9000 & 0.7555 & $l_{1}$ fault \\
\hline & $\left(30^{\circ}, 1500 \Omega\right)$ & -0.6972 & -0.5462 & -0.5819 & 0.8233 & 0.7478 & 0.8720 & $l_{1}$ fault \\
\hline & $\left(30^{\circ}, 2000 \Omega\right)$ & -0.7340 & -0.4746 & -0.4987 & 0.8116 & 0.7052 & 0.8649 & $l_{1}$ fault \\
\hline & $\left(60^{\circ}, 10 \Omega\right)$ & -0.6113 & -0.8418 & -0.9606 & 0.8201 & 0.6109 & 0.7682 & $l_{1}$ fault \\
\hline & $\left(60^{\circ}, 100 \Omega\right)$ & -0.8523 & -0.9398 & -0.9703 & 0.9080 & 0.7461 & 0.8808 & $l_{1}$ fault \\
\hline & $\left(60^{\circ}, 500 \Omega\right)$ & -0.9027 & -0.9822 & -0.9407 & 0.9268 & 0.9015 & 0.9374 & $l_{1}$ fault \\
\hline & $\left(60^{\circ}, 1000 \Omega\right)$ & -0.8862 & -0.7425 & -0.9420 & 0.8639 & 0.9368 & 0.7823 & $l_{1}$ fault \\
\hline & $\left(60^{\circ}, 1500 \Omega\right)$ & -0.9137 & -0.7322 & -0.7302 & 0.8450 & 0.7847 & 0.8721 & $l_{1}$ fault \\
\hline & $\left(60^{\circ}, 2000 \Omega\right)$ & -0.8855 & -0.9129 & -0.8872 & 0.8027 & 0.7284 & 0.8894 & $l_{1}$ fault \\
\hline & $\left(90^{\circ}, 10 \Omega\right)$ & -0.9293 & -0.8728 & -0.9691 & 0.9117 & 0.8795 & 0.7960 & $l_{1}$ fault \\
\hline & $\left(90^{\circ}, 100 \Omega\right)$ & -0.9464 & -0.9790 & -0.9820 & 0.9549 & 0.8879 & 0.9346 & $l_{1}$ fault \\
\hline & $\left(90^{\circ}, 500 \Omega\right)$ & -0.9714 & -0.8578 & -0.9932 & 0.8990 & 0.9487 & 0.8150 & $l_{1}$ fault \\
\hline & $\left(90^{\circ}, 1000 \Omega\right)$ & -0.9846 & -0.8524 & -0.8428 & 0.8467 & 0.7932 & 0.8995 & $l_{1}$ fault \\
\hline & $\left(90^{\circ}, 1500 \Omega\right)$ & -0.9812 & -0.8457 & -0.7970 & 0.8033 & 0.7265 & 0.9038 & $l_{1}$ fault \\
\hline & $\left(90^{\circ}, 2000 \Omega\right)$ & -0.9732 & -0.8092 & -0.7535 & 0.7408 & 0.6597 & 0.9216 & $l_{1}$ fault \\
\hline
\end{tabular}

TABLE 3: Cross-correlation coefficient with $\left(l_{1}, 90^{\circ}\right.$, and $\left.2000 \Omega\right)$ fault situation.

\begin{tabular}{lccccccc}
\hline $\begin{array}{l}\text { Faulty } \\
\text { line }\end{array}$ & $\rho_{12}$ & $\rho_{13}$ & $\rho_{14}$ & $\rho_{23}$ & $\rho_{24}$ & $\rho_{34}$ & Result \\
\hline$l_{1}$ & -0.9732 & -0.8092 & -0.7535 & 0.7408 & 0.6597 & 0.9216 & $l_{1}$ \\
\hline
\end{tabular}

performance of the method, we added $0.5 \mathrm{db}$ or $-0.5 \mathrm{db}$ noise intensity to TZSC when fault in different line occurred and set signal before fault as 0 . The selection results and specific cross-correlation coefficients are shown in Tables 4 and 5, respectively.

Signal-to-noise ratio equaling $-0.5 \mathrm{db}$ and fault situations as $\left(l_{2}, 60^{\circ}, 1500 \Omega\right)$ are taken as an illustration. The TZSC with noise of $l_{2}$ and $i_{c}(t)$ of $l_{2}$ are shown in Figures 7(c) and 7(d), and the cross-correlation coefficients are shown in Table 6.

Firstly, from the faulty line selection method and Table 6, cross-correlation coefficients $\rho_{2 q}$ of $l_{2}$ and other lines are all negative, so the output is " -1 " and $\rho_{j q}$ of other lines are different, so the output is "1"; therefore, we judge line $l_{2}$ as faulty line, which is consistent with actual fault situation. Then, comparison of Figures 7(c) and 7(d) shows that, with the disturbance of strong noise, even if the TZSC of each line is submerged in strong noise, the proposed method is still able to effectively extract the changing trend of TZSC in initial stage and can accurately judge the faulty line. Finally,
Tables 4 and 5 indicate that, with the disturbance of different noise intensity, the changing trends of characteristic currents in initial stage between faulty line and nonfaulty line still have a better discrimination after the treatment of VSBS, so we can say the method shows a good antinoise performance. The definition of signal-to-noise ratio [28] shows that the smaller the ratio is, the larger the noise intensity will be; therefore, antinoise performance of the method in this paper is much better than the one proposed in [8], which added $15 \mathrm{db}$ and $0.5 \mathrm{db}$ noise.

\subsection{Adaptation Analysis of Faulty Line Selection Method}

5.4.1. Different Faulty Lines. When fault occurs in $l_{2}, l_{3}$, and $l_{4}$, respectively, we carry out faulty line selection method proposed in the paper to verify its adaptability, and the results and specific cross-correlation coefficients are shown in Table 7.

We know from [25] that, with the introduction of cable lines, although the attenuation process of fault transient current becomes shorter, the frequency spectrum principal component of transient component will move to low frequency band, which helps to detect VSBS. Therefore, different line fault conditions will not affect selection results of the method, and excellent results can also be obtained with different fault resistance. 


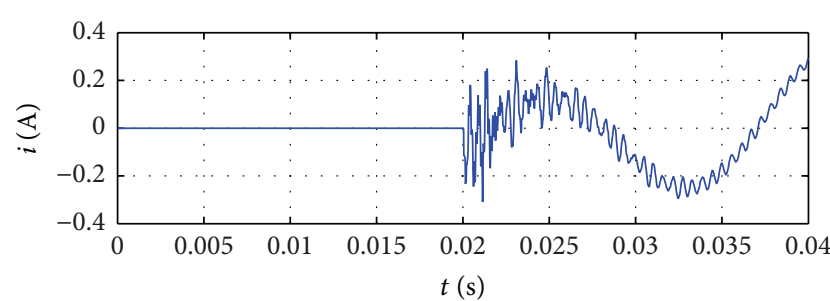

(a) TZSC of $l_{2}$ in the $\left(l_{1}, 90^{\circ}, 2000 \Omega\right)$

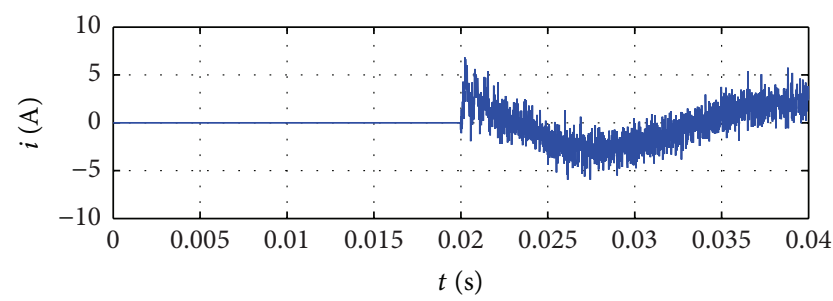

(c) TZSC of $l_{2}$ in the $\left(l_{2}, 60^{\circ}, 1500 \Omega\right)$

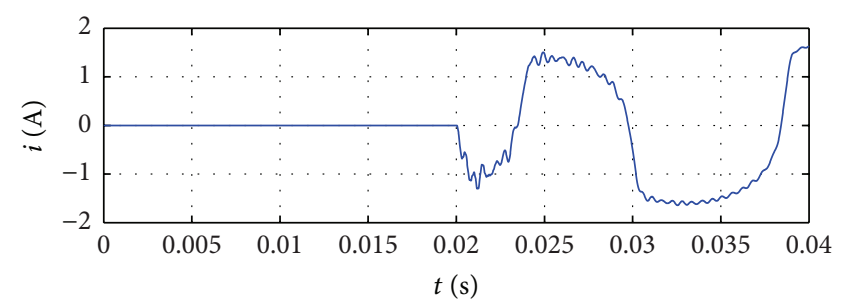

(b) $i_{c}(t)$ of $l_{2}$ in the $\left(l_{1}, 90^{\circ}, 2000 \Omega\right)$

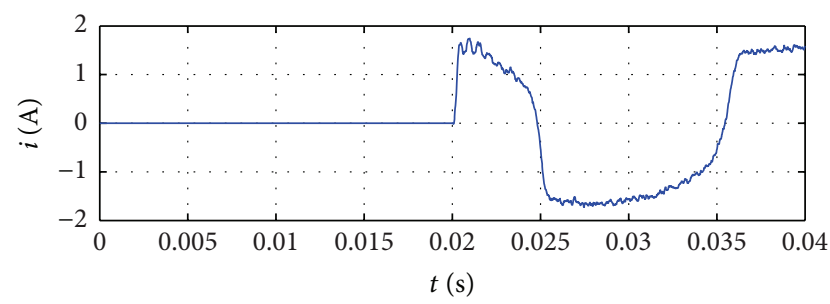

(d) $i_{c}(t)$ of $l_{2}$ in the $\left(l_{2}, 60^{\circ}, 1500 \Omega\right)$

FIgURE 7: The TZSC and characteristic current of $l_{2}$ for different fault condition.

TABLE 4: Adding $0.5 \mathrm{db}$ Gauss white noise.

\begin{tabular}{lcccccccc}
\hline Faulty line & Fault situation & $\rho_{12}$ & $\rho_{13}$ & $\rho_{14}$ & $\rho_{23}$ & $\rho_{24}$ & $\rho_{34}$ & Judgment result \\
\hline$l_{1}$ & $\left(0^{\circ}, 300 \Omega\right)$ & $\mathbf{- 0 . 5 4 2 6}$ & $\mathbf{- 0 . 7 0 4 3}$ & $\mathbf{- 0 . 7 1 4 8}$ & -0.4045 & 0.3447 & 0.9060 & $l_{1}$ fault \\
& $\left(90^{\circ}, 1300 \Omega\right)$ & $\mathbf{- 0 . 7 1 8 3}$ & $-\mathbf{0 . 8 1 6 5}$ & $-\mathbf{0 . 9 7 3 3}$ & 0.5301 & 0.6960 & 0.7200 & $l_{1}$ fault \\
\hline \multirow{2}{*}{$l_{2}$} & $\left(30^{\circ}, 400 \Omega\right)$ & $\mathbf{- 0 . 7 5 6 2}$ & 0.8406 & 0.8673 & $\mathbf{- 0 . 8 4 3 5}$ & $\mathbf{- 0 . 8 5 7 3}$ & 0.9282 & $l_{2}$ fault \\
& $\left(60^{\circ}, 1500 \Omega\right)$ & $\mathbf{- 0 . 5 7 3 2}$ & 0.5756 & 0.5700 & $\mathbf{- 0 . 9 4 6 6}$ & $-\mathbf{0 . 9 0 1 9}$ & 0.8969 & $l_{2}$ fault \\
\hline \multirow{2}{*}{$l_{3}$} & $\left(60^{\circ}, 200 \Omega\right)$ & 0.6424 & $\mathbf{- 0 . 7 4 3 9}$ & 0.7361 & $\mathbf{- 0 . 7 9 9 7}$ & 0.5996 & $-\mathbf{0 . 8 8 9 0}$ & $l_{3}$ fault \\
& $\left(90^{\circ}, 2000 \Omega\right)$ & 0.4531 & $-\mathbf{0 . 1 2 7 9}$ & 0.1332 & $\mathbf{- 0 . 4 2 1 3}$ & 0.4255 & $-\mathbf{0 . 9 9 5 0}$ & $l_{3}$ fault \\
\hline \multirow{2}{*}{$l_{4}$} & $\left(0^{\circ}, 600 \Omega\right)$ & 0.1898 & 0.2342 & $\mathbf{- 0 . 1 3 0 0}$ & 0.8282 & $\mathbf{- 0 . 0 3 1 4}$ & $\mathbf{- 0 . 3 7 5 5}$ & $l_{4}$ fault \\
& $\left(30^{\circ}, 1700 \Omega\right)$ & 0.8354 & 0.8258 & $\mathbf{- 0 . 1 2 2 1}$ & 0.8843 & $\mathbf{- 0 . 1 1 3 0}$ & $\mathbf{- 0 . 0 4 6 4}$ & $l_{4}$ fault \\
\hline
\end{tabular}

TABLE 5: Adding $-0.5 \mathrm{db}$ Gauss white noise.

\begin{tabular}{|c|c|c|c|c|c|c|c|c|}
\hline Faulty line & Fault situation & $\rho_{12}$ & $\rho_{13}$ & $\rho_{14}$ & $\rho_{23}$ & $\rho_{24}$ & $\rho_{34}$ & Judgment result \\
\hline \multirow{2}{*}{$l_{1}$} & $\left(0^{\circ}, 300 \Omega\right)$ & -0.5919 & -0.6906 & -0.6985 & 0.8092 & 0.7142 & 0.9197 & $l_{1}$ fault \\
\hline & $\left(90^{\circ}, 1300 \Omega\right)$ & -0.4888 & -0.8292 & -0.9956 & -0.5549 & 0.4627 & 0.8320 & $l_{1}$ fault \\
\hline \multirow{2}{*}{$l_{2}$} & $\left(30^{\circ}, 400 \Omega\right)$ & -0.7433 & 0.8314 & 0.8227 & -0.8555 & -0.8542 & 0.9247 & $l_{2}$ fault \\
\hline & $\left(60^{\circ}, 1500 \Omega\right)$ & -0.6892 & 0.5295 & 0.7051 & -0.8987 & -0.8958 & 0.8216 & $l_{2}$ fault \\
\hline \multirow{2}{*}{$l_{3}$} & $\left(60^{\circ}, 200 \Omega\right)$ & 0.5730 & -0.4954 & 0.3834 & -0.8823 & 0.6574 & -0.8804 & $l_{3}$ fault \\
\hline & $\left(90^{\circ}, 2000 \Omega\right)$ & 0.3280 & -0.5827 & 0.6395 & -0.5173 & 0.4422 & -0.9832 & $l_{3}$ fault \\
\hline \multirow{2}{*}{$l_{4}$} & $\left(0^{\circ}, 600 \Omega\right)$ & 0.6865 & 0.7746 & -0.2193 & 0.8570 & -0.0483 & -0.4239 & $l_{4}$ fault \\
\hline & $\left(30^{\circ}, 1700 \Omega\right)$ & 0.3201 & 0.6745 & -0.3900 & 0.6954 & -0.5253 & -0.7236 & $l_{4}$ fault \\
\hline
\end{tabular}

TABLE 6: Cross-correlation coefficients with $\left(l_{2}, 60^{\circ}\right.$, and $\left.1500 \Omega\right)$ fault situation.

\begin{tabular}{lccccccc}
\hline $\begin{array}{l}\text { Faulty } \\
\text { line }\end{array}$ & $\rho_{12}$ & $\rho_{13}$ & $\rho_{14}$ & $\rho_{23}$ & $\rho_{24}$ & $\rho_{34}$ & Result \\
\hline$l_{2}$ & $\mathbf{- 0 . 6 8 9 2}$ & 0.5295 & 0.7051 & $\mathbf{- 0 . 8 9 8 7}$ & $\mathbf{- 0 . 8 9 5 8}$ & 0.8216 & $l_{2}$ \\
\hline
\end{tabular}

5.4.2. Different Fault Distance. Since the distance of fault point is different in actual fault situations, we carry out simulation of line $l_{1}$, with different distance from the bus line, and the fault distance is set as $4.5 \mathrm{~km}, 7.5 \mathrm{~km}, 10.5 \mathrm{~km}$, and $13.5 \mathrm{~km}$, respectively. Select the faulty line with the method and the results are shown in Table 8 , with specific crosscorrelation coefficients shown in Table 8.

It can be seen that the selection results are consistent with actual fault situation, which indicates that the method can also achieve faulty line selection of fault with different distance situation, especially with high ground resistance in the end of line. 
TABLE 7: Results of fault in different line.

\begin{tabular}{|c|c|c|c|c|c|c|c|c|}
\hline Faulty line & Fault situation & $\rho_{12}$ & $\rho_{13}$ & $\rho_{14}$ & $\rho_{23}$ & $\rho_{24}$ & $\rho_{34}$ & Judgment result \\
\hline \multirow{8}{*}{$l_{2}$} & $\left(0^{\circ}, 200 \Omega\right)$ & -0.6531 & 0.9323 & 0.9305 & -0.6822 & -0.6978 & 0.9235 & $l_{2}$ fault \\
\hline & $\left(0^{\circ}, 1200 \Omega\right)$ & -0.7730 & 0.4276 & 0.5390 & -0.2614 & -0.3268 & 0.6480 & $l_{2}$ fault \\
\hline & $\left(30^{\circ}, 300 \Omega\right)$ & -0.8426 & 0.9380 & 0.9252 & -0.8706 & -0.8636 & 0.9173 & $l_{2}$ fault \\
\hline & $\left(30^{\circ}, 1600 \Omega\right)$ & -0.7976 & 0.4731 & 0.5823 & -0.4084 & -0.4836 & 0.6704 & $l_{2}$ fault \\
\hline & $\left(60^{\circ}, 50 \Omega\right)$ & -0.9389 & 0.9236 & 0.9220 & -0.9775 & -0.9866 & 0.9468 & $l_{2}$ fault \\
\hline & $\left(60^{\circ}, 500 \Omega\right)$ & -0.9552 & 0.9591 & 0.9292 & -0.9702 & -0.9210 & 0.9186 & $l_{2}$ fault \\
\hline & $\left(90^{\circ}, 100 \Omega\right)$ & -0.9745 & 0.9646 & 0.9611 & -0.9881 & -0.9833 & 0.9640 & $l_{2}$ fault \\
\hline & $\left(90^{\circ}, 2000 \Omega\right)$ & -0.3466 & 0.3401 & 0.2875 & -0.9268 & -0.9663 & 0.8184 & $l_{2}$ fault \\
\hline \multirow{8}{*}{$l_{3}$} & $\left(0^{\circ}, 200 \Omega\right)$ & 0.2988 & -0.2088 & 0.7533 & -0.5504 & 0.3707 & -0.4434 & $l_{3}$ fault \\
\hline & $\left(0^{\circ}, 1200 \Omega\right)$ & 0.4411 & -0.5978 & 0.4780 & -0.1951 & 0.4098 & -0.1930 & $l_{3}$ fault \\
\hline & $\left(30^{\circ}, 300 \Omega\right)$ & 0.3693 & -0.4231 & 0.7843 & -0.5670 & 0.3883 & -0.6595 & $l_{3}$ fault \\
\hline & $\left(30^{\circ}, 1600 \Omega\right)$ & 0.5930 & -0.5245 & 0.5808 & -0.2329 & 0.5754 & -0.3471 & $l_{3}$ fault \\
\hline & $\left(60^{\circ}, 50 \Omega\right)$ & 0.5844 & -0.5267 & 0.4706 & -0.8439 & 0.7423 & -0.9695 & $l_{3}$ fault \\
\hline & $\left(60^{\circ}, 500 \Omega\right)$ & 0.5631 & -0.7989 & 0.8680 & -0.5192 & 0.5302 & -0.8409 & $l_{3}$ fault \\
\hline & $\left(90^{\circ}, 100 \Omega\right)$ & 0.6357 & -0.7711 & 0.6803 & -0.6946 & 0.5872 & -0.9779 & $l_{3}$ fault \\
\hline & $\left(90^{\circ}, 2000 \Omega\right)$ & 0.7254 & -0.3280 & 0.2684 & -0.7031 & 0.6408 & -0.9910 & $l_{3}$ fault \\
\hline \multirow{8}{*}{$l_{4}$} & $\left(0^{\circ}, 200 \Omega\right)$ & 0.8296 & 0.8473 & -0.0548 & 0.9663 & -0.0947 & -0.1597 & $l_{4}$ fault \\
\hline & $\left(0^{\circ}, 1200 \Omega\right)$ & 0.7250 & 0.5219 & -0.4825 & 0.8572 & -0.4005 & -0.1097 & $l_{4}$ fault \\
\hline & $\left(30^{\circ}, 300 \Omega\right)$ & 0.8040 & 0.8457 & -0.1849 & 0.9636 & -0.2711 & -0.2791 & $l_{4}$ fault \\
\hline & $\left(30^{\circ}, 1600 \Omega\right)$ & 0.7594 & 0.5734 & -0.4455 & 0.8304 & -0.3052 & -0.1994 & $l_{4}$ fault \\
\hline & $\left(60^{\circ}, 50 \Omega\right)$ & 0.6962 & 0.4713 & -0.1996 & 0.7384 & -0.2860 & -0.7616 & $l_{4}$ fault \\
\hline & $\left(60^{\circ}, 500 \Omega\right)$ & 0.8955 & 0.9260 & -0.4905 & 0.9621 & -0.5296 & -0.5718 & $l_{4}$ fault \\
\hline & $\left(90^{\circ}, 100 \Omega\right)$ & 0.8089 & 0.8493 & -0.8635 & 0.9817 & -0.9673 & -0.9873 & $l_{4}$ fault \\
\hline & $\left(90^{\circ}, 2000 \Omega\right)$ & 0.8014 & 0.3311 & -0.4829 & 0.6891 & -0.8129 & -0.9470 & $l_{4}$ fault \\
\hline
\end{tabular}

TABLE 8: Results of fault with different distance.

\begin{tabular}{|c|c|c|c|c|c|c|c|c|}
\hline Faulty line & Fault situation & $\rho_{12}$ & $\rho_{13}$ & $\rho_{14}$ & $\rho_{23}$ & $\rho_{24}$ & $\rho_{34}$ & Judgment result \\
\hline \multirow{6}{*}{$l_{1}(4.5 \mathrm{~km})$} & $\left(0^{\circ}, 10 \Omega\right)$ & -0.4489 & -0.8020 & -0.8974 & 0.7467 & 0.5894 & 0.7566 & $l_{1}$ fault \\
\hline & $\left(0^{\circ}, 100 \Omega\right)$ & -0.6667 & -0.7359 & -0.7554 & 0.8437 & 0.6847 & 0.8680 & $l_{1}$ fault \\
\hline & $\left(0^{\circ}, 500 \Omega\right)$ & -0.5742 & -0.7155 & -0.6577 & 0.9012 & 0.8383 & 0.9043 & $l_{1}$ fault \\
\hline & $\left(0^{\circ}, 1000 \Omega\right)$ & -0.6003 & -0.3521 & -0.7290 & 0.7853 & 0.7477 & 0.6978 & $l_{1}$ fault \\
\hline & $\left(0^{\circ}, 1500 \Omega\right)$ & -0.6861 & -0.2790 & -0.3324 & 0.7096 & 0.6051 & 0.8424 & $l_{1}$ fault \\
\hline & $\left(0^{\circ}, 2000 \Omega\right)$ & -0.7598 & -0.2504 & -0.2922 & 0.6492 & 0.5343 & 0.8500 & $l_{1}$ fault \\
\hline \multirow{6}{*}{$l_{1}(7.5 \mathrm{~km})$} & $\left(0^{\circ}, 10 \Omega\right)$ & -0.6947 & -0.9639 & -0.9391 & 0.7768 & 0.7641 & 0.9503 & $l_{1}$ fault \\
\hline & $\left(0^{\circ}, 100 \Omega\right)$ & -0.7154 & -0.7370 & -0.7452 & 0.9116 & 0.7875 & 0.9062 & $l_{1}$ fault \\
\hline & $\left(0^{\circ}, 500 \Omega\right)$ & -0.5624 & -0.7148 & -0.6455 & 0.8987 & 0.8371 & 0.8998 & $l_{1}$ fault \\
\hline & $\left(0^{\circ}, 1000 \Omega\right)$ & -0.5985 & -0.3462 & -0.7319 & 0.7675 & 0.7272 & 0.6817 & $l_{1}$ fault \\
\hline & $\left(0^{\circ}, 1500 \Omega\right)$ & -0.6824 & -0.2807 & -0.3355 & 0.6925 & 0.5808 & 0.8271 & $l_{1}$ fault \\
\hline & $\left(0^{\circ}, 2000 \Omega\right)$ & -0.7538 & -0.2572 & -0.2988 & 0.6381 & 0.5127 & 0.8316 & $l_{1}$ fault \\
\hline \multirow{6}{*}{$l_{1}(10.5 \mathrm{~km})$} & $\left(0^{\circ}, 10 \Omega\right)$ & -0.5543 & -0.9069 & -0.9374 & 0.7530 & 0.6665 & 0.9332 & $l_{1}$ fault \\
\hline & $\left(0^{\circ}, 100 \Omega\right)$ & -0.7379 & -0.7404 & -0.7442 & 0.9511 & 0.8637 & 0.9347 & $l_{1}$ fault \\
\hline & $\left(0^{\circ}, 500 \Omega\right)$ & -0.5586 & -0.7198 & -0.6388 & 0.9008 & 0.8435 & 0.8981 & $l_{1}$ fault \\
\hline & $\left(0^{\circ}, 1000 \Omega\right)$ & -0.6028 & -0.3422 & -0.7371 & 0.7592 & 0.7194 & 0.6716 & $l_{1}$ fault \\
\hline & $\left(0^{\circ}, 1500 \Omega\right)$ & -0.6842 & -0.2810 & -0.3374 & 0.6827 & 0.5661 & 0.8183 & $l_{1}$ fault \\
\hline & $\left(0^{\circ}, 2000 \Omega\right)$ & -0.7533 & -0.2619 & -0.3028 & 0.6323 & 0.4989 & 0.8188 & $l_{1}$ fault \\
\hline \multirow{6}{*}{$l_{1}(13.5 \mathrm{~km})$} & $\left(0^{\circ}, 10 \Omega\right)$ & -0.9348 & -0.9142 & -0.9543 & 0.9721 & 0.9623 & 0.9682 & $l_{1}$ fault \\
\hline & $\left(0^{\circ}, 100 \Omega\right)$ & -0.7530 & -0.7467 & -0.7521 & 0.9639 & 0.9094 & 0.9508 & $l_{1}$ fault \\
\hline & $\left(0^{\circ}, 500 \Omega\right)$ & -0.5585 & -0.7284 & -0.6356 & 0.9039 & 0.8536 & 0.8981 & $l_{1}$ fault \\
\hline & $\left(0^{\circ}, 1000 \Omega\right)$ & -0.6121 & -0.3380 & -0.7439 & 0.7569 & 0.8223 & 0.6670 & $l_{1}$ fault \\
\hline & $\left(0^{\circ}, 1500 \Omega\right)$ & -0.6914 & -0.2798 & -0.3368 & 0.6780 & 0.5608 & 0.8176 & $l_{1}$ fault \\
\hline & $\left(0^{\circ}, 2000 \Omega\right)$ & -0.7582 & -0.2654 & -0.3038 & 0.6312 & 0.4937 & 0.8124 & $l_{1}$ fault \\
\hline
\end{tabular}


TABLE 9: Selection results of different time length.

\begin{tabular}{lcc}
\hline Time length & Sample size & Accuracy \\
\hline $0.005 \mathrm{~s}$ & 112 & $110 / 112$ \\
$0.01 \mathrm{~s}$ & 112 & $107 / 112$ \\
$0.015 \mathrm{~s}$ & 112 & $71 / 112$ \\
\hline
\end{tabular}

5.4.3. Influence of Different Initial Stage Length on Selection Accuracy. From the moment of fault occurrence, choose time length of different initial stage as $0 \sim 0.005 \mathrm{~s}, 0 \sim 0.01 \mathrm{~s}$, and $0 \sim$ $0.015 \mathrm{~s}$, initial fault angle as $0^{\circ}, 30^{\circ}, 60^{\circ}$, and $90^{\circ}$, respectively, fault resistance as $10 \Omega, 50 \Omega, 100 \Omega, 500 \Omega, 1000 \Omega, 1500 \Omega$, and $2000 \Omega$, and faulty line as $l_{1}, l_{2}, l_{3}$, and $l_{4}$, respectively, that is, a total of $4 \times 7 \times 4=112$ different fault conditions. Then, use the method proposed in the paper to carry out faulty line selection, and the selection results as shown in Table 9.

Table 9 shows that time length of the initial stage can affect the selection accuracy. The longer the length of initial stage is, the lower the selection accuracy will be. The main reasons are as follows:

(1) VSBS can well detect the changing trend of TZSC in initial stage, besides, TZSC is an oscillation attenuation signal whose initial value is 0 , therefore, with smaller time length, and the cross-correlation coefficient has better representation.

(2) When single phase-to-ground fault occurs in distribution network, TZSC of each line will increase suddenly, and the TZSC mutation direction between faulty line and nonfaulty line is opposite. However, in the following $T / 4$ time period, this situation will not happen, so the increase of signal length will affect the overall changing trend of the signal and $\rho_{1}$ and, then, cause wrong judgment.

(3) It is known from Section 3 that, with the increase of time length, $\rho_{1}$ would also decrease, which means that the characteristic current can not well extract the changing trend of TZSC, and it would lead to wrong judgment.

5.5. Adaptation Analysis of Faulty Line Selection Method. In order to compare with other faulty line selection methods, choose TZSC with $\left(l_{4}, 90^{\circ}\right.$, and $\left.10 \Omega\right)$ fault situation as an example, and demonstrate it from the following two cases, respectively: with noise and without noise. With the disturbance of noise, signal-to-noise ratio of the added noise is $-0.5 \mathrm{db}$, and antinoise performances of existing methods are emphatically analyzed. At the end, in different faulty conditions, the selection results, which are from different faulty line selection methods, are given.

\subsubsection{Without Disturbance of Noise}

VSBS Method. According to the method in the paper, input TZSC of each line to VSBS, use fourth-order RungeKutta method for numerical simulation, and calculate crosscorrelation coefficients of every line $i_{c}(t)$, the results of which are shown in Table 10. Choose characteristic current of $l_{3}$ and display its waveform in $0.019 \mathrm{~s} \sim 0.021 \mathrm{~s}$, as is shown in Figure 8(a).

Wavelet Packet Method. We use db10 wavelet packet to decompose TZSC of each line by four layers. Choose characteristic frequency band according to the maximum energy selection principle [32], restructure it with single branch, and calculate cross-correlation coefficient of every frequency band, whose results are shown in Table 10. Choose characteristic frequency band of $l_{3}$ and display its waveform in $0 \sim 50$, as is shown in Figure 8(b).

Wavelet Method. We use db10 wavelet to decompose TZSC of each line by four layers. Choose the approximation coefficients of the four-layer wavelet of each line as characteristic signal, restructure it with single branch, and calculate crosscorrelation coefficient after the restructuring of every characteristic signal, the results of which are shown in Table 10. Choose approximation coefficient waveform of line $l_{3}$ and display its waveform in $0.019 \mathrm{~s} \sim 0.021 \mathrm{~s}$ which is shown in Figure 8(c).

EMD Method. We use EMD algorithm [33] to decompose TZSC of each line. Choose the first intrinsic mode components (IMF1 component) after treatment as characteristic mode component, calculate cross-correlation coefficient of each IMF1 component, and the results are shown in Table 10. Choose IMF1 component of line $l_{3}$ and display its waveform in $0.019 \mathrm{~s} \sim 0.021 \mathrm{~s}$, which is shown in Figure 8(d).

Firstly, for waveform, the changing trend of initial stage waveform in Figure 8(a) is clearer than that in Figure 8(b), indicating that VSBS can better describe the changing trend of TZSC compared to wavelet packet transform, because when the initial value is 0 , the brown particles are in potential peak position of bistable system, and any small disturbance will make the brown particles of bistable system move drastically, so the bistable system can well track the signal changing trend. Oscillating components in Figure 8(b) are more abundant than that in Figure 8(a), which means that the characteristic signal processed by wavelet packet could contain more frequency components; the reason is that wavelet packet has such good capability of time-frequency analysis that it can elaborately divide the high frequency and low frequency of signals, while the frequency compression and transformation of VSBS will make some frequency components lost.

The waveform of Figure 8(a) changed after fault occurred, and the changing amplitude is larger than that before fault, while the waveform of Figure 8(c) changed before fault occurred, and the changing amplitude after fault occurred is smaller than that before fault, showing that VSBS can better reflect the changing time and trend of TZSC compared to wavelet transform. In addition, the oscillation degree of Figure 8(c) is smaller than that of Figure 8(b), indicating that although wavelet transform has good time-frequency localization, its high frequency resolution is poor.

The oscillation degree of Figure 8(d) is the strongest, because IMF component obtained by EMD contains 
TABLE 10: Cross-correlation coefficient of different signal processing algorithm without noise.

\begin{tabular}{lccccccc}
\hline Signal processing & $\rho_{12}$ & $\rho_{13}$ & $\rho_{14}$ & $\rho_{23}$ & $\rho_{24}$ & $\rho_{34}$ & Result \\
\hline VSBS & 0.9065 & 0.6112 & -0.5938 & 0.7582 & -0.7103 & -0.9876 & $l_{4}$ \\
Wavelet packet & -0.4887 & -0.0218 & -0.2531 & 0.6983 & -0.5990 & -0.9548 & Error \\
Wavelet & 0.4483 & -0.1536 & -0.6129 & 0.1580 & -0.9549 & 0.0137 \\
EMD & 0.1968 & 0.4415 & -0.2457 & 0.3389 & -0.8920 & -0.3948 & Error \\
\hline
\end{tabular}

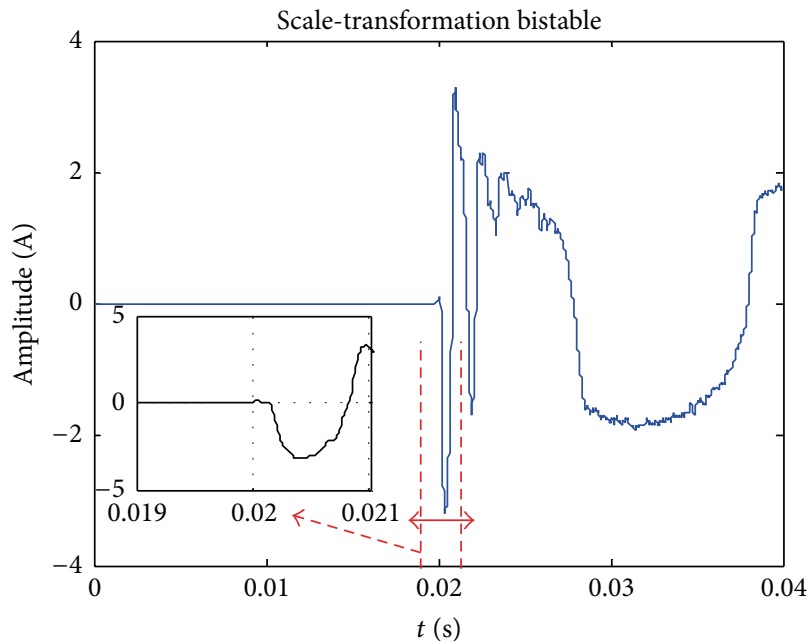

(a)

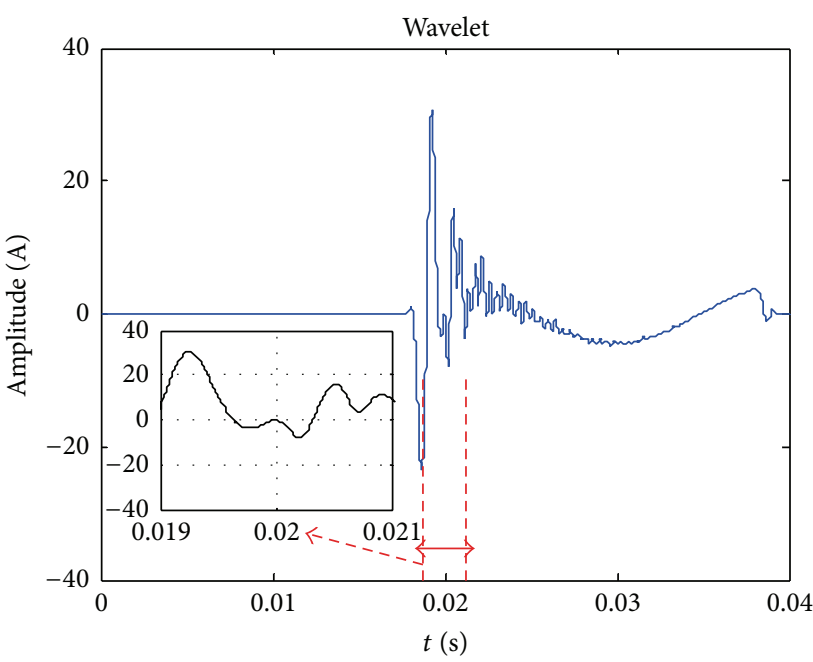

(c)

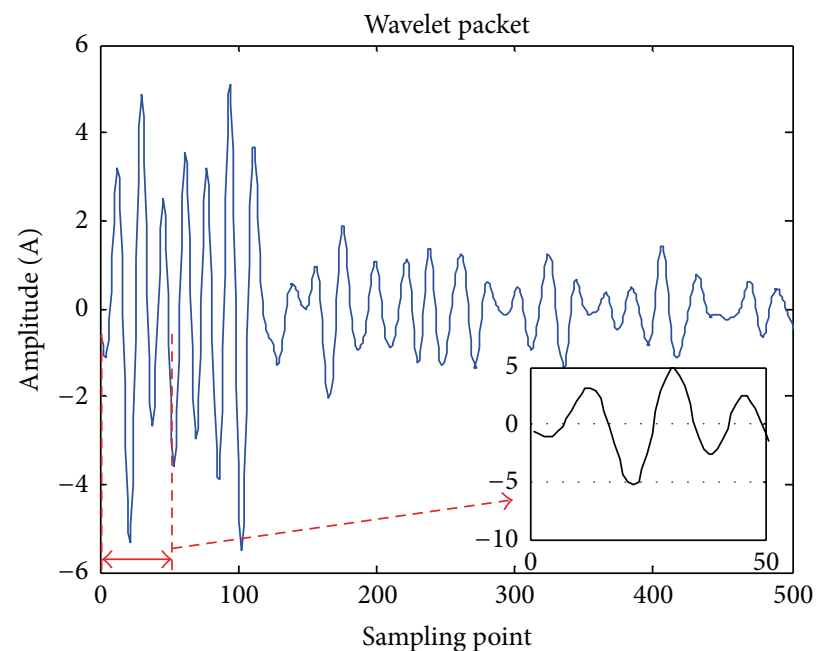

(b)

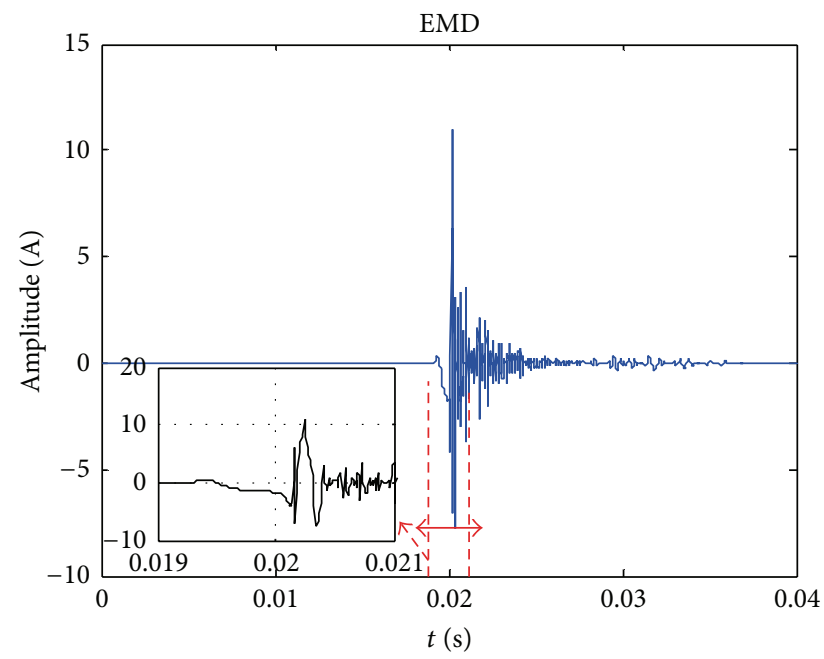

(d)

FIGURE 8: Characteristic signal of $l_{3}$ extracted by different signal processing algorithm without noise.

frequency component which changes with the signal itself and is more suitable for nonstationary signals like TZSC. However, similar to Figure 8(c), Figure 8(d) also changed before fault occurred, indicating that EMD algorithm has a weaker ability to describe changing time and trend of TZSC compared to VSBS.

Then, from the cross-correlation coefficient and faulty line selection results we can see that, with the method proposed in this paper, after processing with VSBS and EMD, only the cross-correlation coefficients of TZSC between line $l_{4}$ and other lines are all the same, so line $l_{4}$ is judged as faulty line, which is consistent with actual situations. However, processed by wavelet packet, the cross-correlation coefficients between characteristic signal of line $l_{1}$ and other lines are equal to $-0.4887,-0.0218$, and -0.2531 , respectively, all of which are the same negative sign, and, in the same way, the cross-correlation coefficients between $l_{4}$ and other lines are equal to $-0.2531,-0.5990$, and -0.9548 , respectively, which are also the same sign, so $l_{1}$ and $l_{4}$ are judged as faulty line, but this result is not consistent with actual fault situation. 


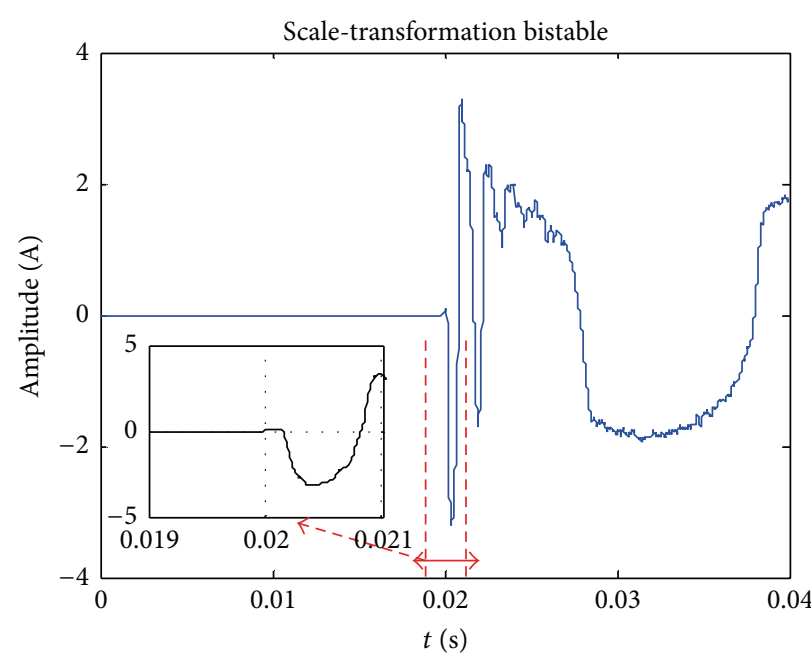

(a)

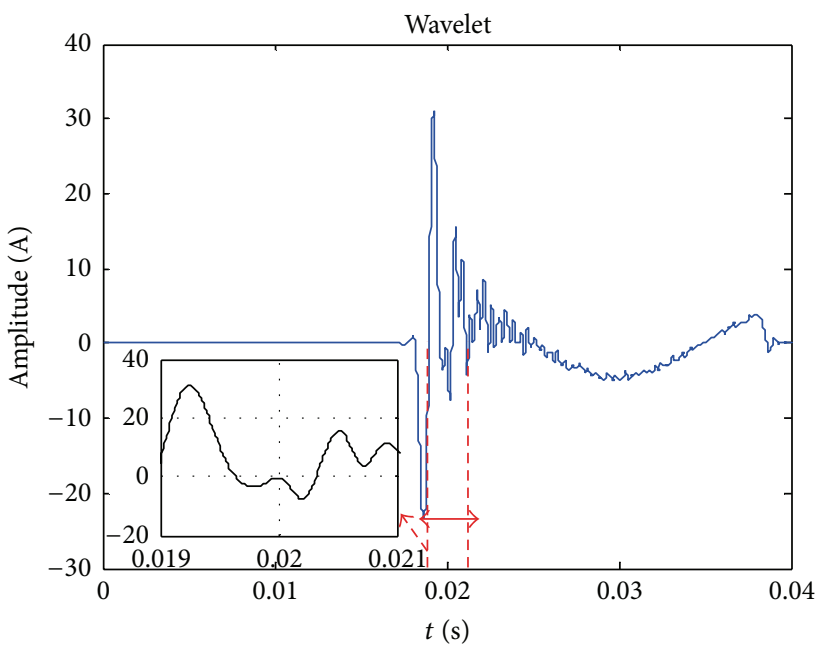

(c)

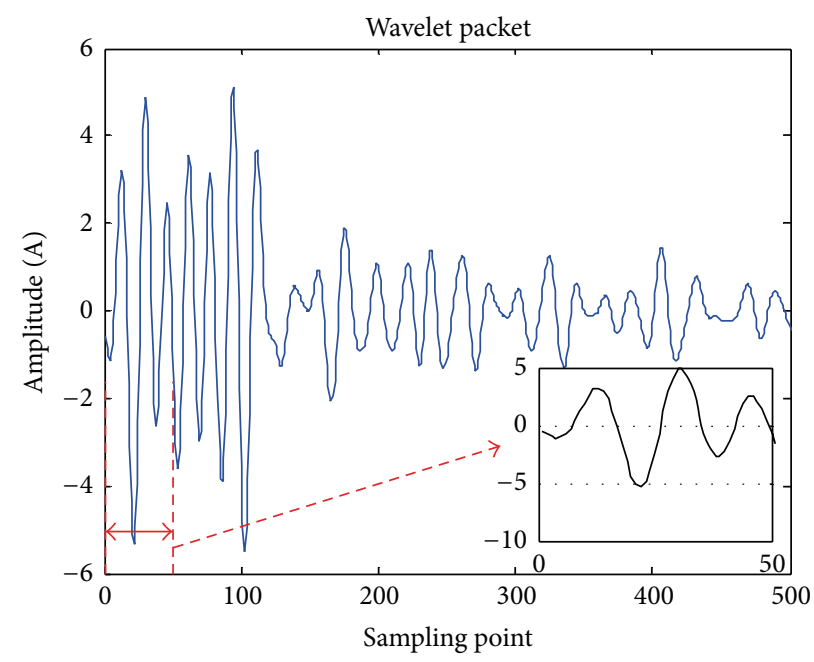

(b)

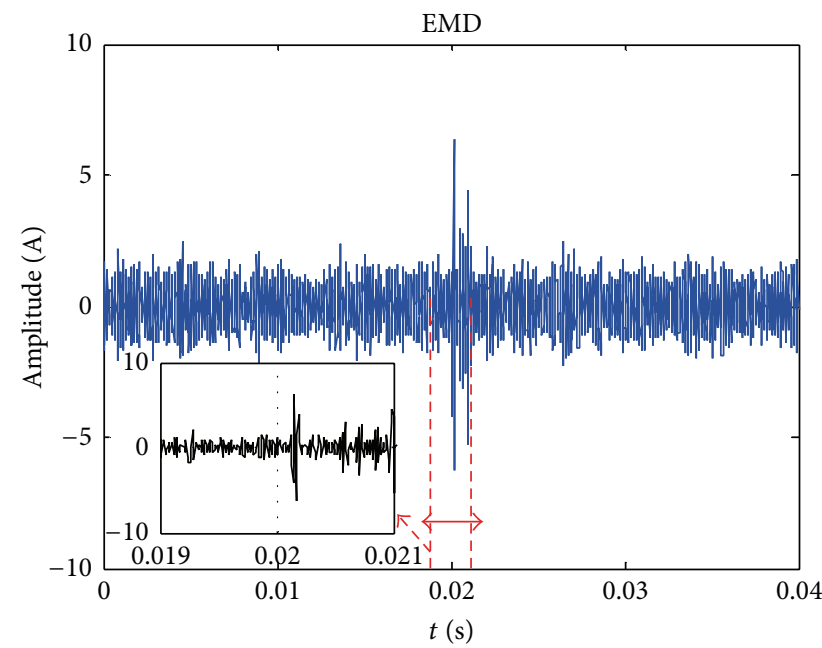

(d)

FIGURE 9: Characteristic signal of $l_{3}$ extracted by different signal processing algorithm with noise.

TABLE 11: Cross-correlation coefficient of different signal processing algorithm with noise.

\begin{tabular}{lccccccc}
\hline Signal processing method & $\rho_{12}$ & $\rho_{13}$ & $\rho_{14}$ & $\rho_{23}$ & $\rho_{24}$ & $\rho_{34}$ & Result \\
\hline VSBS & 0.9193 & 0.6179 & -0.5949 & 0.7604 & -0.7152 & -0.9889 & $l_{4}$ \\
Wavelet packet & -0.4851 & -0.0997 & -0.2113 & 0.7048 & -0.6111 & -0.9429 & Error \\
Wavelet & 0.4328 & -0.1579 & -0.6183 & 0.1505 & -0.9500 & 0.0231 & Error \\
EMD & -0.4851 & -0.0997 & -0.2113 & 0.7048 & -0.611 & -0.9429 & Error \\
\hline
\end{tabular}

And, then, processed by wavelet algorithm, none of the crosscorrelation coefficients of characteristic signal between one line and other lines are the same sign, so all the lines are judged as healthy line, which, obviously, is not consistent with actual situation. This shows that wavelet transform and wavelet packet transform are not suitable for faulty line selection in this paper.

5.5.2. With Disturbance of Noise. With the same method and steps of Section 5.5.1, taking the waveform of line $l_{3}$ in $0.019 \mathrm{~s} \sim 0.021 \mathrm{~s}$ as an example, we add a strong noise with signal-to-noise ratio as $-0.5 \mathrm{db}$ for simulation, the results of which are shown in Figure 9 and Table 11. Figure 9(a) is obtained by the process of VSBS, Figure $9(\mathrm{~b})$ is obtained by the process of wavelet packet algorithm, Figure $9(\mathrm{c})$ is obtained by the process of wavelet transform algorithm, and Figure $9(\mathrm{~d})$ is obtained by the process of EMD algorithm.

As to waveform, there are no obvious differences between other figures and Figure 8 except that Figure $9(\mathrm{~d})$ is submerged in noise. As to cross-correlation coefficients, we will choose cross-correlation coefficient between line $l_{1}$ and line $l_{2}$ for analysis: without noise, processed in turn by VSBS, 
TABLE 12: The faulty line selection results using VSBS.

\begin{tabular}{|c|c|c|c|c|c|c|c|c|}
\hline Faulty line & Fault situation & $\rho_{12}$ & $\rho_{13}$ & $\rho_{14}$ & $\rho_{23}$ & $\rho_{24}$ & $\rho_{34}$ & Judgment result \\
\hline \multirow{2}{*}{$l_{1}$} & $\left(0^{\circ}, 600 \Omega\right)$ & -0.5728 & -0.7529 & -0.6276 & 0.8075 & 0.7007 & 0.8648 & $l_{1}$ fault \\
\hline & $\left(90^{\circ}, 1300 \Omega\right)$ & -0.3714 & -0.7972 & -0.9721 & 0.4664 & 0.3556 & 0.7120 & $l_{1}$ fault \\
\hline \multirow{2}{*}{$l_{2}$} & $\left(30^{\circ}, 60 \Omega\right)$ & -0.8249 & 0.8697 & 0.8300 & -0.9433 & -0.9556 & 0.9368 & $l_{2}$ fault \\
\hline & $\left(60^{\circ}, 700 \Omega\right)$ & -0.8470 & 0.8171 & 0.7311 & -0.9788 & -0.9223 & 0.9154 & $l_{2}$ fault \\
\hline \multirow{2}{*}{$l_{3}$} & $\left(90^{\circ}, 1200 \Omega\right)$ & 0.6945 & -0.8165 & 0.7977 & -0.6321 & 0.6379 & -0.9853 & $l_{3}$ fault \\
\hline & $\left(30^{\circ}, 80 \Omega\right)$ & 0.3286 & -0.4111 & 0.3350 & -0.5162 & 0.7632 & -0.6732 & $l_{3}$ fault \\
\hline \multirow{2}{*}{$l_{4}$} & $\left(60^{\circ}, 800 \Omega\right)$ & 0.7923 & 0.5940 & -0.1569 & 0.8881 & -0.4586 & -0.5013 & $l_{4}$ fault \\
\hline & $\left(0^{\circ}, 1000 \Omega\right)$ & 0.1455 & 0.4597 & -0.5422 & 0.6710 & -0.0118 & -0.6022 & $l_{4}$ fault \\
\hline
\end{tabular}

TABLE 13: The faulty line selection results using wavelet packet.

\begin{tabular}{lcccccccc}
\hline Faulty line & Fault situation & $\rho_{12}$ & $\rho_{13}$ & $\rho_{14}$ & $\rho_{23}$ & $\rho_{24}$ & $\rho_{34}$ & Judgment result \\
\hline \multirow{2}{*}{$l_{1}$} & $\left(0^{\circ}, 600 \Omega\right)$ & $\mathbf{- 0 . 4 1 7 6}$ & $-\mathbf{0 . 7 4 7 5}$ & $-\mathbf{0 . 7 3 9 2}$ & 0.0358 & 0.4844 & 0.1128 & $l_{1}$ fault \\
& $\left(90^{\circ}, 1300 \Omega\right)$ & $\mathbf{- 0 . 4 2 9 3}$ & $-\mathbf{0 . 7 0 1 3}$ & $-\mathbf{0 . 6 9 3 1}$ & 0.0363 & 0.4732 & -0.0221 & $l_{1}$ fault \\
\hline \multirow{2}{*}{$l_{2}$} & $\left(30^{\circ}, 60 \Omega\right)$ & -0.0995 & -0.1246 & -0.3036 & -0.5007 & -0.5424 & -0.3091 & Error \\
& $\left(60^{\circ}, 700 \Omega\right)$ & -0.0659 & -0.2447 & 0.0931 & -0.6616 & -0.3810 & -0.4056 & Error \\
\hline \multirow{2}{*}{$l_{3}$} & $\left(90^{\circ}, 1200 \Omega\right)$ & -0.1564 & -0.1681 & -0.2352 & -0.0367 & -0.3298 & -0.8204 & Error \\
& $\left(30^{\circ}, 80 \Omega\right)$ & -0.0819 & -0.2292 & -0.3543 & 0.0630 & -0.2489 & -0.7990 & Error \\
\hline \multirow{2}{*}{$l_{4}$} & $\left(60^{\circ}, 800 \Omega\right)$ & -0.4760 & -0.0045 & -0.6670 & 0.3079 & -0.0135 & -0.7307 & Error \\
& $\left(0^{\circ}, 1000 \Omega\right)$ & -0.4838 & 0.0016 & -0.6757 & 0.2884 & 0.0106 & -0.7269 & $l_{4}$ fault \\
\hline
\end{tabular}

TABLE 14: The faulty line selection results using wavelet.

\begin{tabular}{lccccccccc}
\hline Faulty line & Fault situation & $\rho_{12}$ & $\rho_{13}$ & $\rho_{14}$ & $\rho_{23}$ & $\rho_{24}$ & \multicolumn{2}{c}{$\rho_{34}$} & Judgment result \\
\hline \multirow{2}{*}{$l_{1}$} & $\left(0^{\circ}, 600 \Omega\right)$ & $\mathbf{- 0 . 5 3 3 0}$ & $\mathbf{- 0 . 7 1 5 8}$ & $\mathbf{- 0 . 8 5 7 9}$ & 0.4851 & 0.2899 & 0.5469 & $l_{1}$ fault \\
& $\left(90^{\circ}, 1300 \Omega\right)$ & $-\mathbf{0 . 3 1 8 9}$ & $\mathbf{- 0 . 3 2 5 0}$ & $-\mathbf{0 . 9 1 6 8}$ & 0.2064 & 0.2794 & 0.2527 & $l_{1}$ fault \\
\hline \multirow{2}{*}{$l_{2}$} & $\left(30^{\circ}, 60 \Omega\right)$ & -0.6787 & -0.0655 & 0.6617 & 0.0808 & -0.9550 & -0.2924 & Error \\
& $\left(60^{\circ}, 700 \Omega\right)$ & -0.5115 & 0.3300 & 0.4164 & -0.6453 & -0.8811 & 0.3380 & Error \\
\hline \multirow{2}{*}{$l_{3}$} & $\left(90^{\circ}, 1200 \Omega\right)$ & 0.3446 & $-\mathbf{0 . 3 2 5 4}$ & 0.3109 & $-\mathbf{0 . 3 5 7 7}$ & 0.2208 & $-\mathbf{0 . 9 0 3 7}$ & $l_{3}$ fault \\
& $\left(30^{\circ}, 80 \Omega\right)$ & 0.0951 & -0.0220 & 0.1917 & 0.2228 & 0.1118 & -0.1896 & Error \\
\hline \multirow{2}{*}{$l_{4}$} & $\left(60^{\circ}, 800 \Omega\right)$ & 0.3017 & 0.4761 & $\mathbf{- 0 . 4 8 1 2}$ & 0.6225 & $-\mathbf{0 . 6 5 6 0}$ & $-\mathbf{0 . 8 0 8 2}$ & $l_{4}$ fault \\
& $\left(0^{\circ}, 1000 \Omega\right)$ & 0.0751 & 0.0991 & -0.2497 & 0.6540 & -0.2592 & 0.0464 & Error \\
\hline
\end{tabular}

wavelet packet, and wavelet algorithm, the value is 0.9065 , -0.4887 , and 0.4483 , respectively, while, with noise, processed in turn by VSBS, wavelet packet, and wavelet algorithm, the value is $0.9193,-0.4851$, and 0.4328 , respectively. Thus it can be seen that, with noise, the cross-correlation coefficient values by VSBS, wavelet packet, and wavelet algorithm are of little difference, so all of them have better antinoise ability. However, the cross-correlation coefficient processed by EMD algorithm without noise is 0.1968 , and, with noise, the value is -0.4851 , which changes from positive correlation to negative correlation, and the change is large, so combined with Figure 8(d) we can say that the antinoise ability of EMD algorithm is weak.

In summary, VSBS can extract the changing trend in initial stage of weak TZSC with the disturbance of strong noise, and its performance is better compared to wavelet transform, wavelet packet transform, and EMD algorithm; therefore, we choose VSBS to extract characteristic frequency band of TZSC in this paper.

5.5.3. Faulty Line Selection Results from Different Method. In strong noise background whose signal-to-noise ratio is $-0.5 \mathrm{db}$, when different fault occurs including different lines, faulty resistance, and initial phase, the VSBS, wavelet packet, wavelet, and EMD are employed to select faulty line, respectively, and their faulty line selection results are shown in Tables $12-15$, respectively.

Table 12 shows that VSBS has no misjudgment in strong noise background and different faulty conditions; that is, the VSBS method can select faulty line correctly. However, there are many misjudgments in Tables 13-15. These data indicate further that the antinoise performance of VSBS is better compared to wavelet transform, wavelet packet transform, and EMD algorithm. 
TABLE 15: The faulty line selection results using EMD.

\begin{tabular}{lcccccccc}
\hline Faulty line & Fault situation & $\rho_{12}$ & $\rho_{13}$ & $\rho_{14}$ & $\rho_{23}$ & $\rho_{24}$ & $\rho_{34}$ & Judgment result \\
\hline \multirow{2}{*}{$l_{1}$} & $\left(0^{\circ}, 600 \Omega\right)$ & -0.0014 & -0.0122 & -0.0328 & 0.0103 & -0.0362 & -0.0239 & Error \\
& $\left(90^{\circ}, 1300 \Omega\right)$ & 0.1435 & -0.0413 & 0.0427 & 0.0506 & -0.0252 & 0.0327 & Error \\
\hline \multirow{2}{*}{$l_{2}$} & $\left(30^{\circ}, 60 \Omega\right)$ & -0.0428 & -0.0414 & 0.1031 & -0.0378 & -0.1844 & -0.0168 & Error \\
& $\left(60^{\circ}, 700 \Omega\right)$ & -0.0061 & 0.0327 & 0.0047 & 0.0046 & 0.0319 & -0.0592 & Error \\
\hline \multirow{2}{*}{$l_{3}$} & $\left(90^{\circ}, 1200 \Omega\right)$ & -0.0273 & $-\mathbf{0 . 0 0 7 6}$ & 0.0364 & $\mathbf{0 . 0 4 1 6}$ & 0.0595 & $\mathbf{0 . 0 0 1 0}$ & Error \\
& $\left(30^{\circ}, 80 \Omega\right)$ & -0.0002 & $-\mathbf{0 . 0 2 3 2}$ & 0.0214 & $-\mathbf{0 . 0 6 8 0}$ & 0.0496 & $-\mathbf{0 . 3 6 1 3}$ & $l_{3}$ fault \\
\hline \multirow{2}{*}{$l_{4}$} & $\left(60^{\circ}, 800 \Omega\right)$ & -0.0207 & 0.0271 & $\mathbf{0 . 0 1 2 3}$ & -0.0448 & $\mathbf{0 . 0 2 5 6}$ & $\mathbf{0 . 0 0 7 3}$ & $l_{4}$ fault \\
& $\left(0^{\circ}, 1000 \Omega\right)$ & 0.0370 & -0.0199 & -0.0206 & -0.1296 & 0.0571 & -0.0115 & Error \\
\hline
\end{tabular}

\section{Conclusions}

This paper proposes a novel faulty line selection method for distribution network based on VSBS theory, and our research gets the following conclusions:

(1) VSBS has better recognition for TZSC, which can effectively extract the changing trend of TZSC in initial stage under different fault situations, and the method can accurately judge the faulty line. In addition, VSBS has better antinoise ability, which helps extract the changing trend of weak TZSC with the disturbance of strong noise, and its antinoise performance is better than that of EMD algorithm and harmonic selection criterion.

(2) The changing trend of TZSC in initial stage (0 $0.005 \mathrm{~s}$ ) is used to judge faulty line, which can reduce calculation time and the requirements for hardware. Besides, for the characterization capability of changing time and trend of TZSC in initial stage, the method in this paper is better than wavelet algorithm and wavelet packet algorithm.

(3) The inadequacies of this paper are as follows: the frequency compression ratio is obtained through experiment, which might cause deviation. In addition, high resistance to ground fault with $-10 \mathrm{db}$ strong noise needs further study owing to the insufficient sensitivity of the present research.

\section{Appendix}

Build the simulation model according to the parameters, make fault of line $l_{1}$ occur at the point $5 \mathrm{~km}$ from the bus, and change the initial fault angle $\left(0^{\circ}, 30^{\circ}, 60^{\circ}\right.$, and $\left.90^{\circ}\right)$ as well as ground resistance for simulation. Then, with the proposed selection method, the cross-correlation coefficients of each line and faulty line selection results are shown in Table 2.

Add $0.5 \mathrm{db}$ or $-0.5 \mathrm{db}$ noise intensity to TZSC when fault in different lines occurs. And set signal before fault to 0 . The selection results and specific cross-correlation coefficients are shown in Tables 4 and 5.

In Figure $5, l_{3}$ is cable-overhead line, and $l_{4}$ is pure cable line; we carry out faulty line selection with the method proposed in the paper to verify its adaptability, the results of which are shown in Table 7, and specific cross-correlation coefficients are shown in Table 7.

Since the distance of fault point is different in actual fault situations, we carry out simulation of line $l_{1}$, with different distance from the bus line, and the fault distance is $4.5 \mathrm{~km}$, $7.5 \mathrm{~km}, 10.5 \mathrm{~km}$, and $13.5 \mathrm{~km}$, respectively. Select the faulty line with the method and the results are shown in Table 8.

\section{Notations}

VSBS: Variable scale bistable system

TZSC: Transient zero-sequence current.

\section{Competing Interests}

The authors declare no conflict of interests.

\section{Authors' Contributions}

Xiaowei Wang and Jie Gao conceived and designed the experiments; Jie Gao performed the experiments; Qiming Cheng analyzed the data; Guobing Song, Xiangxiang Wei, and Yanfang Wei contributed reagents/materials/analysis tools; Jie Gao wrote the paper.

\section{Acknowledgments}

This work was supported by National Natural Science Fund (61403127) of China, Science and Technology Research (12B470003, 14A470004, and 14A470001) of Henan Province, and Control Engineering Lab Project (KG2011-15, KG201404) of Henan Province, China, and Doctoral Fund (B2014023) of Henan Polytechnic University, China.

\section{References}

[1] H. K. Shu, The Application of Electrical Engineering Signal Processing, China Electric Power Press, Beijing, China, 2011.

[2] H. K. Shu, Fault Line Selection of Distribution Power System, China Machine Press, Beijing, China, 2008.

[3] Z. C. Pan, H. F. Zhang, F. Zhang, and Z. Sang, "Analysis and modification of signal injection based fault line selection protection," Automation of Electric Power Systems, vol. 31, no. 4, pp. 71-75, 2007 (Chinese). 
[4] J. Liu, X. Q. Zhang, X. Y. Chen, B. Shen, X. Dong, and Z. Zhang, "Fault location and service restoration for distribution networks based on coordination of centralized intelligence and distributed intelligence," Power System Technology, vol. 37, no. 9, pp. 2608-2614, 2013 (Chinese).

[5] G. K. Ni, H. Bao, L. Zhang, and Y. Yang, "Criterion based on the fault component of zero sequence current for online fault location of single-phase fault in distribution network," Proceedings of the Chinese Society of Electrical Engineering, vol. 30, no. 31, pp. 118-122, 2010.

[6] L. Zhang, P. Yang, D. M. Si, C. Qi, and Y. Yang, "Online fault location of neutral point ungrounded distribution network based on zero-sequence power direction," Automation of Electric Power Systems, vol. 32, no. 17, pp. 79-82, 2008 (Chinese).

[7] X. Z. Dong and S. X. Shi, "Identifying single-phase-to-ground fault feeder in neutral noneffectively grounded distribution system using wavelet transform," IEEE Transactions on Power Delivery, vol. 23, no. 4, pp. 1829-1837, 2008.

[8] X. Wang, J. Gao, X. Wei, and Y. Hou, "A novel fault line selection method based on improved oscillator system of power distribution network," Mathematical Problems in Engineering, vol. 2014, Article ID 901810, 19 pages, 2014.

[9] X. W. Wang, J. W. Wu, and R. Y. Li, "A novel method of fault selection based on voting mechanism of prony relative entropy theroy," Electric Power, vol. 46, no. 1, pp. 59-65, 2013.

[10] S. Zhang, Z.-Y. He, Q. Wang, and S. Lin, "Fault line selection of resonant grounding system based on the characteristics of charge-voltage in the transient zero sequence and support vector machine," Power System Protection and Control, vol. 41, no. 12, pp. 71-78, 2013.

[11] S. Q. Zhang, X. P. Zhai, X. Dong, L. Li, and B. Tang, "Application of EMD and Duffing oscillator to fault line detection in uneffectively grounded system," Proceedings of the CSEE, vol. 33, no. 10, pp. 161-167, 2013.

[12] X. Wang, X. Wei, J. Gao, Y. Hou, and Y. Wei, "Stepped fault line selection method based on spectral kurtosis and relative energy entropy of small current to ground system," Journal of Applied Mathematics, vol. 2014, Article ID 726205, 18 pages, 2014.

[13] J. Zhang, Z. Y. He, and Y. Jia, "Fault line identification approach based on S-transform," Proceedings of CSEE, vol. 31, no. 10, pp. 109-115, 2011.

[14] H. C. Shu, W. Y. Zhao, and S. X. Peng, "Faulty line selection based on HHT detection for hybrid distribution network," Electric Power Automation Equipment, vol. 29, no. 5, pp. 4-10, 2009.

[15] Q. Li and J. Z. Xu, "Power system fault diagnosis based on subjective Bayesian approach," Automation of Electric Power Systems, vol. 31, no. 15, pp. 46-50, 2007.

[16] H. C. Shu, L. Xu, and S. X. Peng, "Correlation analysis for faulty feeder detection in resonant earthed system," Automation of Electric Power Systems, vol. 28, no. 9, pp. 6-9, 2008.

[17] L. P. Wu, C. Huang, D. B. Lin, Z. Zhu, and H. Jiang, "Faulty line selection based on transient wavelet energy for non-solidearthed network," Electric Power Automation Equipment, vol. 33, no. 5, pp. 70-75, 2013.

[18] Y. L. Meng and C. X. Pei, "Stochastic resonance in a bistable system driven by non-Gaussian noise and Gaussian noise," in Proceedings of the IEEE Workshop on Electronics, Computer and Applications (IWECA '14), pp. 358-361, IEEE, Ottawa, Canada, May 2014.

[19] J. Fan, W.-L. Zhao, M.-L. Zhang, R.-H. Tan, and W.-Q. Wang, "Nonlinear dynamics of stochastic resonance and its application in the method of weak signal detection," Acta Physica Sinica, vol. 63, no. 11, Article ID 110506, 2014.

[20] J.-J. Tong, G.-L. Zhang, Q. Cai, J.-M. Jian, and X.-S. Guo, "Application of threshold stochastic resonance in low concentration gas detecting," Journal of Zhejiang University (Engineering Science), vol. 49, no. 1, pp. 15-19, 2015.

[21] S. L. Lu, Q. B. He, F. Hu, and F. Kong, "Sequential multiscale noise tuning stochastic resonance for train bearing fault diagnosis in an embedded system," IEEE Transactions on Instrumentation and Measurement, vol. 63, no. 1, pp. 106-116, 2014.

[22] Y.-B. Li, M.-Q. Xu, H.-Y. Zhao, S.-Y. Zhang, and W.-H. Huang, "Application of cascaded bistable stochastic resonance and Hermite interpolation local mean decomposition method in gear fault diagnosis," Journal of Vibration and Shock, vol. 34, no. 5, pp. 95-101, 2015.

[23] P. E. Greenwood, L. M. Ward, D. F. Russell, A. Neiman, and F. Moss, "Stochastic resonance enhances the electrosensory information available to paddlefish for prey capture," Physical Review Letters, vol. 84, no. 20, pp. 4773-4776, 2000.

[24] H. Xin, "Theoretical study on stochastic resonance in chemical systems," Chinese Journal of Chemical Physics, vol. 13, no. 4, pp. 404-405, 2000.

[25] H. S. Zhang, Z. Y. He, and J. Zhang, "Frequency spectrum characteristic analysis of single-phase grounding fault in resonant grounded systems," Automation of Electric Power Systems, vol. 36, no. 6, pp. 79-84, 2012.

[26] H. C. Shu, L. Gao, and R. M. Duan, "A novel hough transform approach of fault line selection in distribution networks using the total zero-sequence current," Automation of Electric Power Systems, vol. 37, pp. 1-7, 2013.

[27] Y. G. Leng, Mechanism Analysis of the Large Signal ScaleTransformation Stochastic Resonance and Its Engineering Application Study, Tianjin Unibersity, Tianjin, China, 2004.

[28] N. Q. Hu, The Theory and Method of Detection of Weak Characteristic Signal Based on Stochastic Resonance, National Defense Industry Press, Beijing, China, 2012.

[29] X. N. Kang, X. Liu, and J. L. Sounan, "New method for fault line seclection in non-solidly grounded system based on matrix pencil method," Automation of Electric Power Systems, vol. 36, no. 12, pp. 88-93, 2012.

[30] M. F. Guo, S. D. Liu, and G. J. Yang, "A new approach to detect fault line in resonant earthed system based on Hilbert spectrum band-pass filter and transient waveform recognition," Advanced Technology of Electrical Engineering and Energy, vol. 32, no. 3, pp. 67-74, 2013.

[31] Z. J. Kang, D. D. Li, and X. L. Liu, "Faulty line selection with non-power frequency transient components of distribution network," Electric Power Automation Equipment, vol. 31, no. 4, pp. 1-6, 2011.

[32] Z. Y. He, Application of Power Transient Signal Based on Wavelet Analysis, China Electric Power Press, Beijing, China, 2011.

[33] X. W. Wang, Y. D. Li, and S. Tian, "A novel single-phase to ground fault location method based on EMD and ApEn algorithm for small current to ground system," Journal of Computational Information Systems, vol. 8, no. 13, pp. 5629-5637, 2012. 


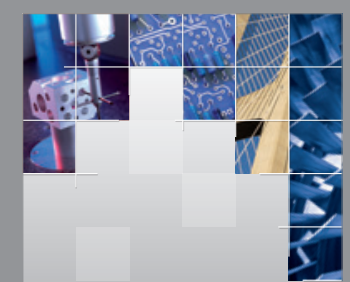

\section{Enfincering}
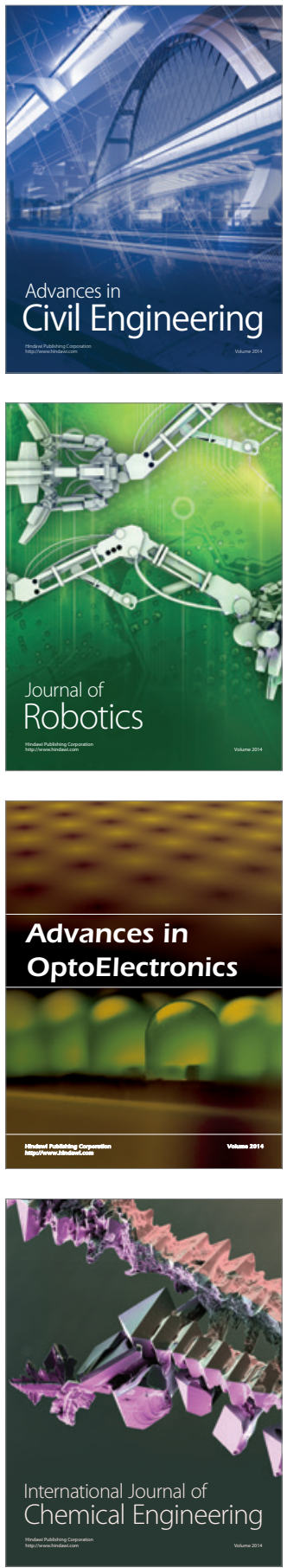

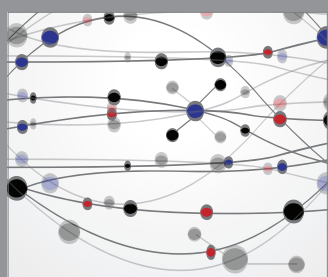

The Scientific World Journal

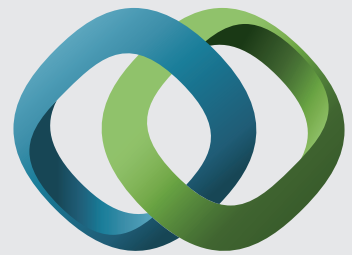

\section{Hindawi}

Submit your manuscripts at

http://www.hindawi.com
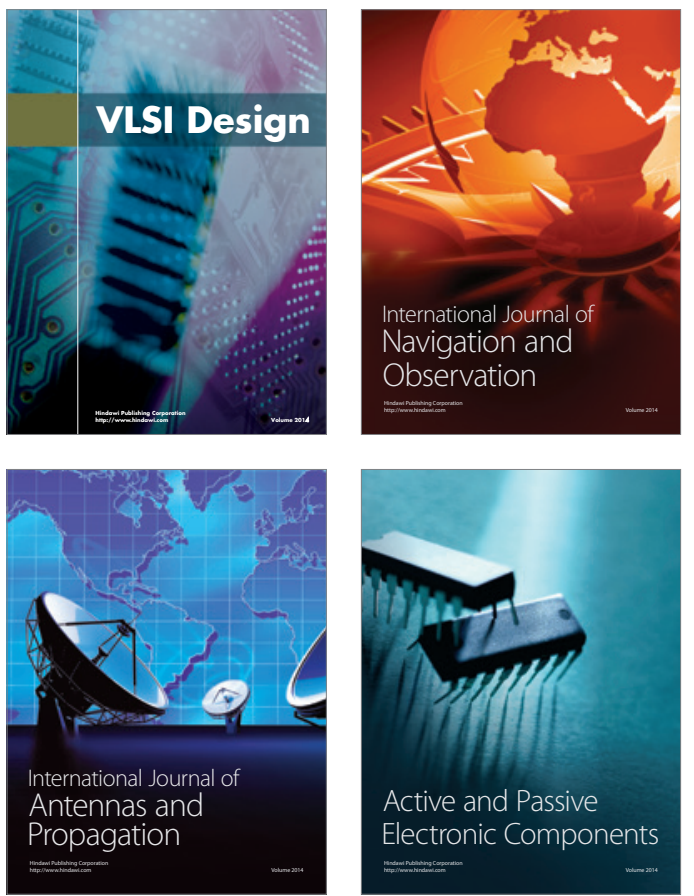
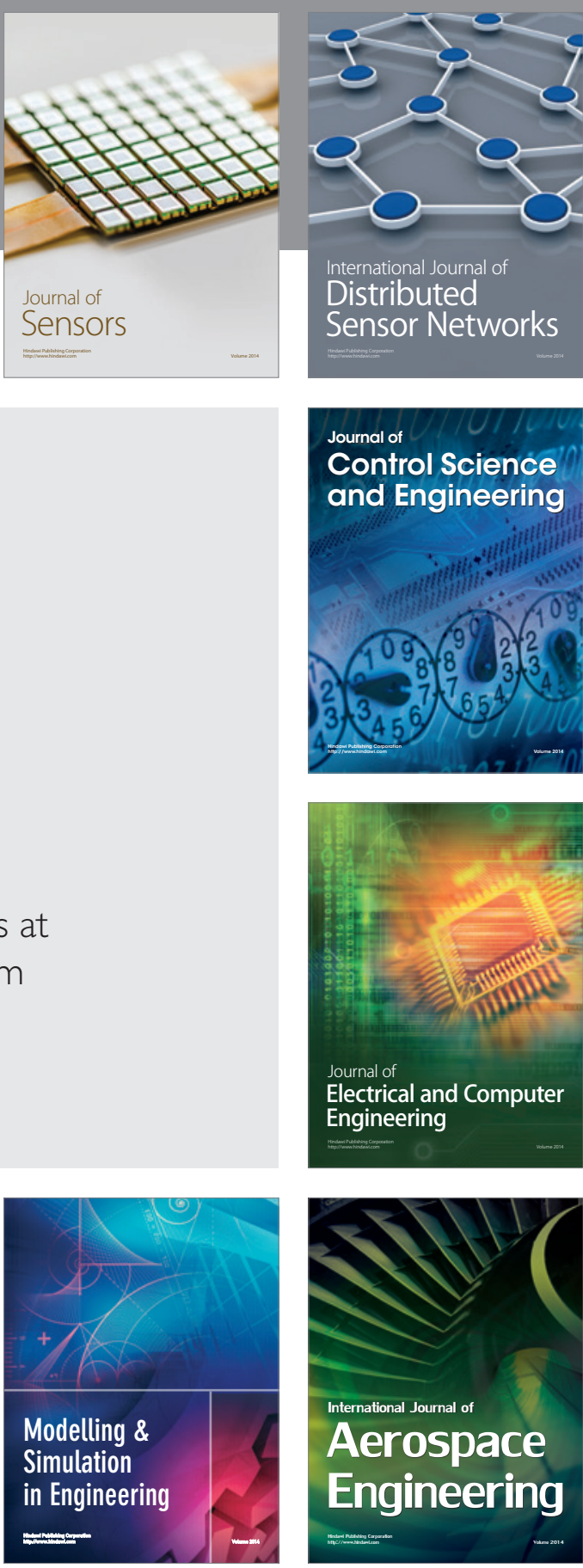

International Journal of

Distributed

Sensor Networks

Journal of

Control Science

and Engineering
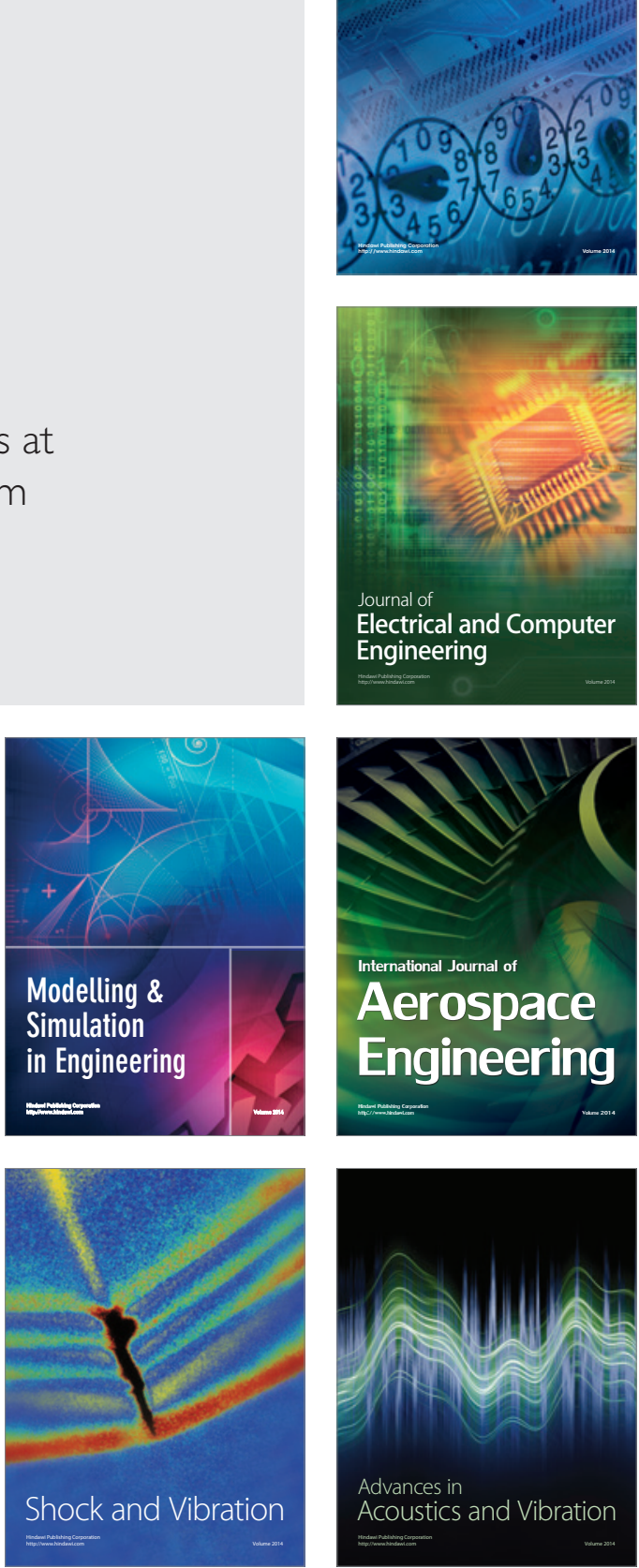